OPEN ACCESS

Edited by:

Francisco Lopez-Munoz, Camilo José Cela University, Spain

Reviewed by:

Jose Antonio Guerra, Complutense University of

Madrid, Spain

Rosa Jurado Barba, Research Institute Hospital

October 12, Spain

${ }^{*}$ Correspondence:

Luca Cucullo

luca.cucullo@ttuhsc.edu

Specialty section:

This article was submitted to Neuropharmacology,

a section of the journal

Frontiers in Pharmacology

Received: 15 August 2019 Accepted: 15 November 2019 Published: 06 December 2019

Citation:

Archie SR and Cucullo L (2019)

Harmful Effects of Smoking Cannabis: A Cerebrovascular and Neurological Perspective.

Front. Pharmacol. 10:1481. doi: 10.3389/fphar.2019.01481

\section{Harmful Effects of Smoking Cannabis: A Cerebrovascular and Neurological Perspective}

\author{
Sabrina Rahman Archie $^{1}$ and Luca Cucullo ${ }^{1,2 *}$ \\ 1 Department of Pharmaceutical Sciences, Texas Tech University Health Sciences Center, Amarillo, TX, United States, \\ ${ }^{2}$ Center for Blood Brain Barrier Research, Texas Tech University Health Sciences Center, Amarillo, TX, United States
}

Apart from being used as a medicine, cannabis or marijuana is the most widely abused recreational drug all over the world. The legalization and decriminalization of cannabis in Canada and various states of USA may be the underlying reason of the widespread popularity of it among young population. Various studies have reported about the relationship between cannabis use and different detrimental effects like cardiovascular, cerebrovascular, and neurological complications among different age groups. Specifically, the young population is getting adversely affected by this, harmful yet, readily accessible recreational drug. Although the mechanism behind cannabis mediated neurological and cerebrovascular complications has not been elucidated yet, the results of these studies have confirmed the association of these diseases with cannabis. Given the lack of comprehensive study relating these harmful complications with cannabis use, the aim of this narrative literature review article is to evaluate and summarize current studies on cannabis consumption and cerebrovascular/neurological diseases along with the leading toxicological mechanisms.

Keywords: oxidative stress, cannabis, recreational, drug, abuse, cerebrovascular, neurodegenerative, stroke

\section{INTRODUCTION}

Cannabis, commonly termed as marijuana, weed, pot, and ganja, is the most widely used illicit recreational drug around the world (Thomas et al., 2014; Wolff and Jouanjus, 2017). It is extracted from the natural plant Cannabis sativa and among more than 60 cannabinoids, tetrahydrocannabinol is one of the major active ingredients of cannabis (Atakan, 2012). In addition to the natural source, the use of synthetic cannabis (SC) named as spice, K2 or Kronic has gained popularity during the last decade (Wolff and Jouanjus, 2017). In spite of using cannabis in medicinal purposes as antioxidant, anticonvulsant, anti-inflammatory, and neuroprotective, the detrimental effects of it cannot be denied (Ford et al., 2017). Acute and chronic use of cannabis is associated with different harmful effects on central nervous system and peripheral system including hyperemesis syndrome, impaired coordination and performance, anxiety, suicidal/tendencies, psychotic symptoms and mood disorders, cannabis withdrawal symptoms, exacerbation of psychotic disorders, neurocognitive impairment, cardiovascular, neurological, respiratory, cerebrovascular, peripheral vascular diseases (Thomas et al., 2014; Karila et al., 2014), pneumomediastinum, pneumothorax, pneumopericardium, bullous lung 
disease, increased risk of chronic obstructive pulmonary disease, desquamated interstitial disease, and appearance of brown pigmented macrophages (Milroy and Parai, 2011).

Despite having serious effects of marijuana in human health, its use has been legalized in Canada and different states of USA. The Canadian Parliament passed Bill C-45, the Cannabis Act to legalize and regulate the production, distribution, and consumption of cannabis on June 19, 2018, and its legalization started effective from October 17, 2018 (Crepault, 2018). In case of US, marijuana use has been approved in 34 states for medical purposes (State Medical Marijuana Laws, 2019) and in 10 states for recreational purposes (Marijuana Overview, 2019).

Even though cannabis has medicinal benefit, recent studies have shown that chronic cannabis inhalation may be associated with cerebrovascular disease such as ischemic stroke (Thanvi and Treadwell, 2009) although the underlying mechanism between stroke and cannabis use has not been strongly established yet. Moreover, the hemorrhagic stroke occurrence has been rarely reported in different studies (Goyal et al., 2017). Several neurological disorders such as cognitive dysfunction, behavioral problems, memory, attention deficiency, structural, and functional changes in brain have been observed in different studies related to cannabis exposure (Chadwick et al., 2013; Battistella et al., 2014; Broyd et al., 2016; Szutorisz and Hurd, 2018). Increased use of cannabis or cannabinoids is associated with several complications related to different organs including the neurological and cerebrovascular system in human body. Due to this, exhaustive studies need to be performed to establish the possible link between cannabis inhalation and neurological and cerebrovascular effect. Keeping the popularity of cannabis use in mind, the aim of this review article is to list the neurological and cerebrovascular effects of marijuana inhalation including the probable mechanisms related to these effects.

\section{Methodology}

Three biomedical literature databases, PubMed, Google Scholar, and ScienceDirect were searched up to July 2019. The search was conducted using "cannabis," "cannabinoid," "cannabidiol," "delta9-THC," “endocannabinoids," “CB1 receptor," “CB2 receptor," "cerebrovascular system," "Blood Brain Barrier," "stroke," "neurological disease," "neuroprotective effect," "oxidative stress." Articles dealing with medical use of cannabis were excluded as the aim of our review article is based on harmful effects of cannabis

\footnotetext{
Abbreviations: cAMP, Cyclic adenosine monophosphate; BBB, Blood-Brain Barrier; CBs, Cannabinoids; CBD, Cannabidiol; CBF, Cerebral blood flow; CNS, Central nervous system; COMT, Catechol-O-methyltransferase; COX-2, Cyclooxygenase-2; ECS, Endocannabinoid system; GPCR, G-protein coupled receptor; GSH-Px, Glutathione peroxidase; ICH, Intracerebral hemorrhage; IS, Ischemic strokes; OS, Oxidative stress; NMDA, N-methyl-d-aspartate; NRF2, Nuclear factor erythroid 2-related factor; NVU, Neurovascular unit; PTSD, Posttraumatic stress disorder; RCVS, Reversible cerebral vasoconstriction syndrome; ROS, Reactive Oxygen Species; SAH, Subarachnoid hemorrhage; SC, Synthetic cannabis; SOD, Superoxide dismutase; THC, $\Delta^{9}$-tetrahydrocannabinol; TJ, Tight junctions; 11-OH-THC, 11-hydroxy $\Delta 9$ _Tetra hydrocannabinol; THCCOOH, 11-nor-9-carboxy- $\Delta$ 9-tetrahydrocannbinol; TRPV1, Transient receptor potential cation-channel subfamily V member 1; PPARs, Peroxisome proliferator activator receptors.
}

inhalation on cerebrovascular and neurological system. Case reports based on cannabis inhalation and cerebrovascular diseases were also searched and evaluated for inclusion in this review. Peer-reviewed articles presenting results of experimental studies in animal models and population-based studies were analyzed and presented in this review paper.

\section{What Are Cannabinoids?}

Cannabinoids (CBs) are a group of chemical compounds which have varying affinity to cannabinoid receptors. Generally, cannabinoids can be classified into three groups namely, phytocannabinoids (isolated from natural source, C. sativa), synthetic cannabinoids, and endocannabinoids (Richter et al., 2018). Although cannabinoids can be extracted naturally from the plants, it can also be cultivated indoors using hydroponic and artificial lighting system nowadays. It was first cultivated in Central Asia however gradually it was brought to cultivate all over the world (Singh et al., 2018). Generally, it is collected from three strains of cannabis plant named $C$. sativa, Cannabis indica, and Cannabis ruderalis which differ in the content and amount of the active ingredients called $\Delta^{9}$-tetrahydrocannabinol (THC) and cannabidiol (CBD) (Booth et al., 2017) (see Figure 1) and among these strains, the highest proportion of THC is present in C. sativa. THC was isolated as one of the first phytocannabionoids (Gaoni and Mechoulam, 1964). In the plant C. sativa, this molecule is present as tetrahydrocannabinolic acid which is then decarboxylated to THC (Richter et al., 2018). Usually, the buds and the leaves of the cannabis plants contain the highest amount of psychoactive ingredient, THC. This THC can be taken up from dried buds and leaves by smoking as well as it can be taken in other forms for instance edibles, waxes, oils, liquid incense, or vapor for both medical and recreational uses. For medical purpose, cannabis has been used to treat nausea and vomiting due to chemotherapy, neuropathic pain related to cancer and advanced neurological disorders (Singh et al., 2018). However, the popularity of cannabis use lies in its recreational purposes. Therefore, in spite of being listed as a schedule 1 substance according to the Section 202 of the Controlled Substances Act of 1970 by Drug Enforcement Administration of USA, the use of cannabis has been legalized or decriminalized in different states of USA (Singh et al., 2018).

Besides natural sources, THC compounds can be synthesized for both medical and recreational uses. Since 1985, two synthetic THC compounds named dronabinol and nabilone have been using in USA in capsule forms for treating nausea, vomiting, and weight loss related to chemotherapy and acquired immunodeficiency syndrome. Recently, an oral solution of dronabinol has been approved by US FDA for treating anorexia and nausea/vomiting associated with acquired immunodeficiency syndrome and chemotherapy respectively. Besides, highly potent cannabinoids and cannabimimetics can be synthesized illegally by altering the structure of THC in numerous ways for recreational purposes which have already gained popularity among the users due to its potency, longer duration, and the failure of conventional drug screening tests to recognize the compounds (Gurney et al., 2014). 


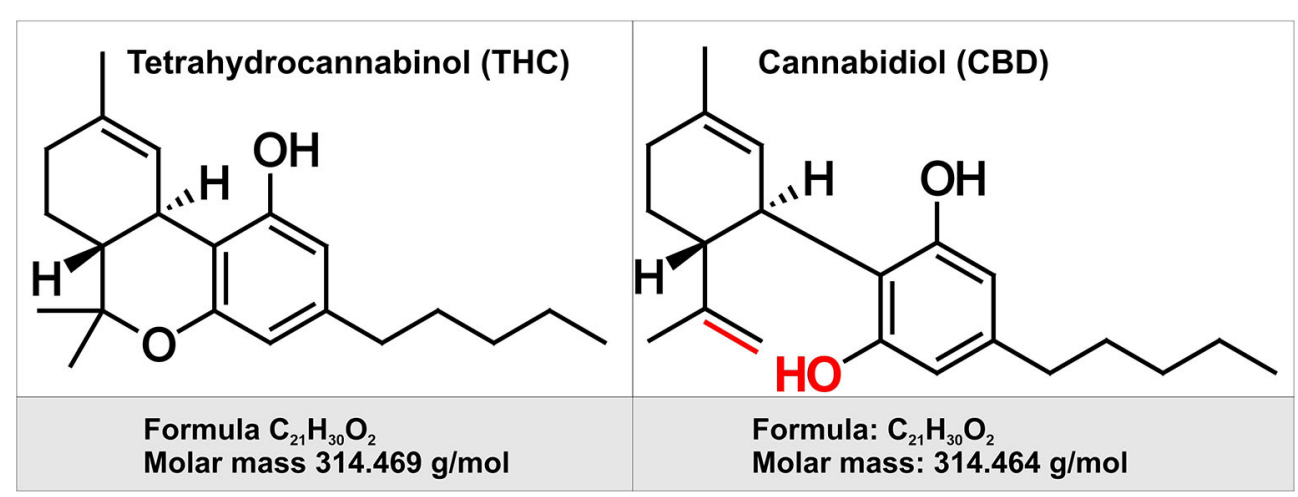

FIGURE 1 | Chemical structure of two of the major cannabinoids contained in Marijuana. Depicted on the left is the chemical structure of tetrahydrocannabinol (THC). THC is the principal psychoactive constituent of cannabis. THC acts as a partial agonist at the cannabinoid receptor CB1 (primarily located in the brain and spinal cord as well as CB2 receptor expressed in cells of the immune system. On the right is depicted the chemical structure of cannabidiol (CBD). By contract with THC, CBD does not have any psychotropic effects, but appears to have some have anti-anxiety and anti-psychotic properties. CBD has a lower affinity for both CB1 and CB2 receptor when compared to THC. Highlighted in red are the chemical structure differences between CBD and THC.

\section{Chemical Composition of C. Sativa}

More than 421 chemicals are present in C. sativa of which 61 chemicals are cannabinoids. During cannabis smoking, over 2,000 compounds including hydrocarbon, nitrogenous compounds, amino acids, fatty acid, sugar etc. are produced by pyrolysis and all of these substances are responsible for different pharmacological as well as toxicological properties of cannabis (Sharma et al., 2012).

\section{Pharmacokinetics of Cannabinoids}

Around $20 \%-70 \%$ of THC can be delivered through smoking (Adams and Martin, 1996). Smoking a 500 to $1,000 \mathrm{mg}$ cannabis cigarette provides a THC dose of $0.2-4.4 \mathrm{mg}$ where a pharmacologic effect of cannabis requires a dose of 2-22 mg. The THC level in the brain typically represents only $\sim 1 \%$ of the administered dose and usually corresponds to $2-44 \mu \mathrm{g}$.

THC is absorbed and reaches high blood concentration rapidly after inhalation through lungs (Vandevenne et al., 2000). Due to extensive lipid solubility and large volume of distribution, THC has a long biological half-life (18 h to 4 days) (Adams and Martin, 1996; Ashton, 2001) and gets distributed in adipose tissue, liver, lung, and spleen (Chiarotti and Costamagna, 2000; Sharma et al., 2012). Hydroxylation of THC generates psychoactive compound, 11-hydroxy $\Delta 9$ _tetra hydrocannabinol (11-OH-THC), and further oxidation of this compound yields inactive compound, 11-nor-9-carboxy- $\Delta 9$ tetrahydrocannbinol (THCCOOH) which is important for diagnostic purposes (Musshoff and Madea, 2006). The bioavailability of $\triangle 9 \mathrm{THC}$ depends on several factors including inhalation depth, duration of puff, and breath hold. It has been found that, the systemic bioavailability of THC is around 23$27 \%$ in heavy users whereas the value is $10-14 \%$ in case of occasional users (Sharma et al., 2012). The time to reach maximum plasma concentrations for $\Delta 9$ THC, 11-OH-THC, and $\mathrm{THCCOOH}$ is 8,15 , and $81 \mathrm{~min}$ after onset of smoking, respectively. On the other hand, systemic absorption of THC is relatively slow after oral ingestion compared to inhalation. In case of oral ingestion, the peak plasma concentration of $\Delta 9$ THC was observed after 1-2 h of ingestion which could be further delayed by few hours in some cases (Lemberger et al., 1971; Hollister et al., 1981). The oral bioavailability of $\Delta 9$ THC may be reduced by $4-12 \%$ by extensive hepatic metabolism (Owens et al., 1981).

Regular cannabis use can be defined as taking cannabinoids 10 to 19 times monthly, whereas heavy use can be termed as using 20 times in a month. However, both regular and heavy use of cannabis are related to several chronic health problems including anxiety, depression, and neurocognitive alterations (Hall and Degenhardt, 2009).

\section{Endocannabinoid System}

Cannabinoids interact directly with our body through a complex system named endocannabinoid system which helps to maintain homeostasis of body by regulating metabolism, intercellular communication, appetite, and memory, immune, and pain responses. This endocannabinoid system (ECS) consists of two types of receptors namely CB1 and CB2 (Zou and Kumar, 2018) (see Figure 2). CB receptors mainly belong to the G-protein coupled receptor (GPCR) family, having inhibitory function on the cyclic adenosine monophosphate (cAMP) pathway through intracellular signal transduction (Richter et al., 2018). Although CB1 receptors are scattered all over the body, these are present predominantly in anatomical regions of the brain (Grotenhermen, 2005) related to memory, anxiety, cognition, pain sensory, motor coordination, endocrine function (Herkenham et al., 1990; Adams and Martin, 1996). CB1 receptors have the inhibitory action on cAMP production which is facilitated by the activation of adenyl cyclase inhibitor subunit of $G$ proteins ( $G_{i / 0}$ proteins). Ultimately, this leads to an inhibition of $\mathrm{N}$ and $\mathrm{P} / \mathrm{Q}$ type calcium currents and an activation of A type, inwardly rectifying potassium currents and mitogen activated protein kinase (Sierra et al., 2015) (see Figure 3). 


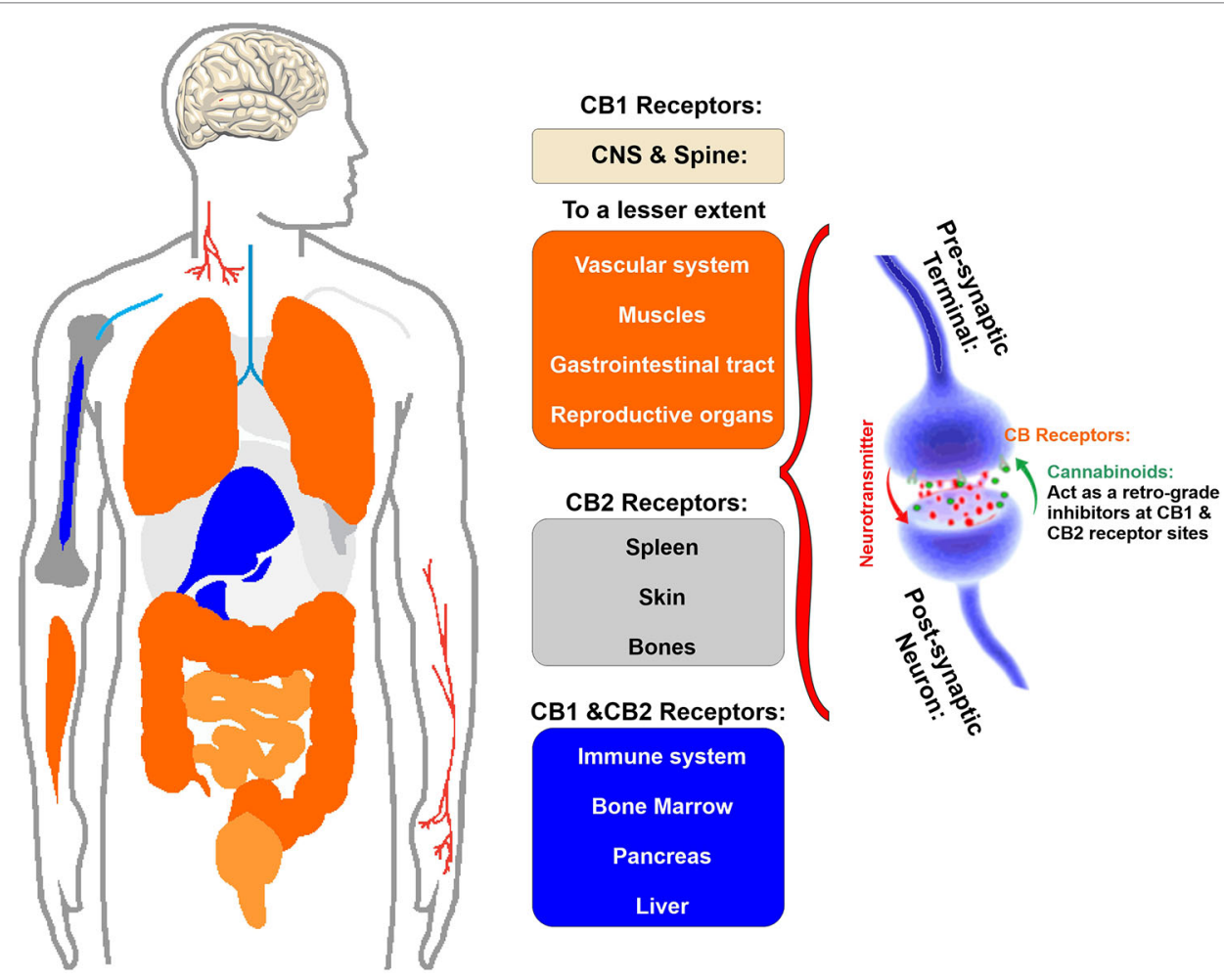

FIGURE 2 | Schematic illustration of the primary location of CB1 and CB2 receptor. Note that CB1 receptor are primarily located in the brain and spinal cord and to a much lesser extent there are also present in the gastrointestinal tract, reproductive organs as well as muscles and vascular system. CB2 receptors are primary located in spleen, skin, and bones as well as the immune cells.

On the other hand, CB2 receptors are located in peripheral nervous system and immune system and the primary function of this receptor is anti-inflammatory activity through initiating an immune response to reduce inflammation as well as tissue damage (Turcotte et al., 2016). Also, it plays a pivotal role in the immune suppressive action of the cannabinoids (Sharma et al., 2012) (see also Figure 2).

The psychoactive agent of cannabis, THC binds with the cannabinoid 1 (CB1) receptor in the brain and the nonpsychoactive component, CBD is the most likely to interact with cannabinoid 2 (CB2) receptor and exert their activities. Therefore, cannabis is used in medical purposes to reduce inflammation, relieve pain, and decrease seizures (RiveraOlmos and Parra-Bernal, 2016; Perucca, 2017).

Moreover, phytocannabinoid $\Delta^{9}$ THC can also bind with other binding sites including the transient receptor potential cation-channel subfamily V member 1 (TRPV1) and peroxisome proliferator activator receptors (PPARs) (O'Sullivan, 2016). Also, GPR 18 receptor has been proposed as a potential cannabinoid receptor (Console-Bram et al., 2014).

\section{Physiology of Cerebrovascular System}

The word cerebrovascular consists of two parts: "cerebro" means large part of the brain and "vascular" refers to arteries and veins. Thus, the cerebrovascular system refers to the blood vessels through which blood is carried out to and from the brain. The cerebrovascular anatomy has an endocranial and exocranial component that can be further divided into the anterior and posterior circulation based on the contribution of blood flow through the internal carotid arteries (ICAs) and vertebral arteries, respectively (Hendricks et al., 2018).

Blood-brain barrier (BBB), a part of the neurovascular unit (NVU), is a unique, dynamic, physical, and biochemical regulatory boundary/barrier which restricts and regulates the exchange of molecules, ions, and cells between the peripheral circulation and central nervous system (CNS) (Yang et al., 2019) and maintains cerebral homeostasis precisely as well (Abdullahi et al., 2018). It transports essential nutrients which are required for the normal metabolism of the brain cells (Sivandzade and Cucullo, 2018). The BBB is primarily composed of endothelial cells, pericytes, and astrocytes restricting the communication between blood and the brain parenchyma (Abbott et al., 2010). As a result, the BBB plays a pivotal role in restraining the entry of neurotoxic plasma components, xenobiotics, blood cells, and pathogens in the brain (Winkler et al., 2011) thus protecting the CNS from inflammation, injury, and different types of diseases (Daneman and Prat, 2015). On contrary, the BBB also limits drug delivery into the brain to treat different neurological diseases (Abbott, 2013; Kaisar et al., 2017).

Disruption of BBB is associated with different neurological disorders for instance stroke, MS, epilepsy, Alzheimer's disease, 

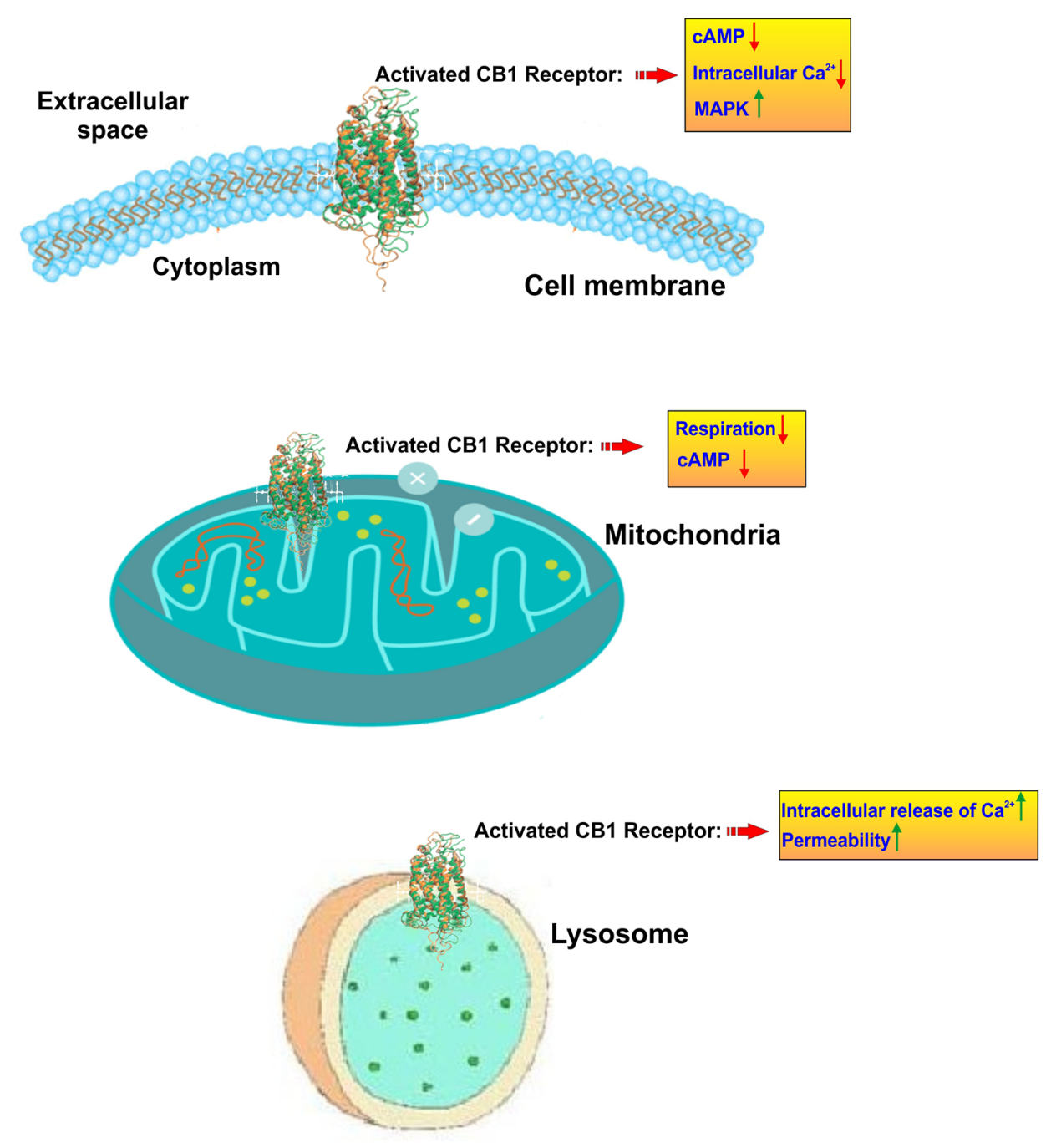

FIGURE 3 | Subcellular localization and activity of CB1 receptors. CB1 receptors are primary located on the cell membrane where their activation lead to inhibition of adenylate cyclase and a resulting reduction of cyclic AMP. In parallel CB1 activation promotes the upregulation of mitogen-activated protein kinase (MAPK) which is involved in directing cellular responses to mitogens, heat shock, osmotic stress, and proinflammatory stimuli (e.g. cytokines). At the mitochondrial level, CB1 activation leads to inhibition of mitochondrial respiration and production of CAMP. CB1 receptors are also present at the level of lysosomes where they prompt a release of calcium from these internal storage units and increase the intracellular calcium levels. Lysosome permeability is also increased.

traumatic brain injury etc. (Abbott et al., 2010; Abbott and Friedman, 2012). Breakdown of BBB has been observed in many functional imaging of human patients and postmortem brain samples in various neurological diseases. This breakdown not only causes edema and disrupts ionic homeostasis but also results in altered signaling and immune infiltration. As a consequence, BBB breakdown leads to neuronal dysregulation and ultimately to neuronal degeneration (Daneman and Prat, 2015).

\section{Effect of Cannabis Inhalation on the Cerebrovascular System}

Studies on acute neurovascular events related to cannabis use have appeared as early as 1964 (Mohan and Sood, 1964). Stroke is the fifth leading cause of death in USA (Vijayan et al., 2019) and recent preclinical studies, population based study, case reports, and reviews have portrayed the correlation of cannabis (both naturally and synthetically derived) to ischemic and hemorrhagic cerebrovascular diseases (Rose et al., 2015) which clearly suggests that cannabis plays a pivotal role in the etiology of cerebral stroke (Wolff et al., 2015a).

\section{Animal Studies}

To examine the effect of cannabinoids on blood circulation as well as reactive vasodilation or vasoconstriction, particularly focusing on the cerebral vascular bed, several studies on rat, mouse, rabbit, cat, and pig models were performed (Richter et al., 2018). It was found from various studies that, both vasodilation and vasoconstriction have been observed following administration of $\Delta^{9}$ THC, 11-OH-THC, AEA, and AM-404 in rodents. However, vasodilation has been observed after administering Abn-CBD and O-1966. On the other hand, all 
perfused cerebral vessels reacted with wall relaxation in case of large mammals (Richter et al., 2018).

From studies in isolated cerebral vessel of rabbit and cat, it has been found that cannabinoid mediated vasodilation through CB1 receptor by inhibiting $\mathrm{Ca}^{+}$influx in cerebral arterial muscle cell as well as possibly through arachidonic acid metabolism (Ellis et al., 1995; Gebremedhin et al., 1999). Additionally, three studies on rat models (Bloom et al., 1997; Stein et al., 1998; Iring et al., 2013) partially indicated the occurrence of vasoconstriction which may result in hypoperfusion by a reduction of $\mathrm{CBF}$ and could be a mechanism of neuronal death through ischemia (Richter et al., 2018). Other studies involving rat and pig models have demonstrated the cerebrovascular dilation due to cannabinoids perfusion (Hillard et al., 2007; MacIntyre et al., 2014; Su et al., 2015).

No study reported any possible mechanism underlying vasoconstrictive effect due to cannabis. It has also been suggested that, vasodilating effect could be beneficial or detrimental depending on the time of vasodilation after CNS insult. As vasodilation reduces the peripheral resistance and increases $\mathrm{CBF}$, this may serve as a protective mechanism and increase oxygen supply in case of a cerebral insult. This protective mechanism may be beneficial in early stages of ischemia. However, if it happens in a later stage, it might augment the recuperation of cerebral function (Richter et al., 2018). As these studies were conducted in different variety of animal models involving different experimental setup, cannabinoid molecules, and their respective doses, it is difficult to draw any conclusion (Richter et al., 2018).

\section{Case Reports}

A total of 107 case reports involving cannabis (both raw and synthetic) intake and neurovascular complications have been studied since 1964 to 2019 (Table 1) and it has been postulated from all these reports that there may be a link between these two events although this correlation has not been established strongly yet.

From these studies we can conclude that among the 107 neurovascular cases, almost $84 \%$ were ischemic stroke related to cannabis or cannabinoid use (both natural and synthetic). Considering Table $\mathbf{1}$ it is found that, young population is experiencing alarming number of neurovascular complications due to recreational use of cannabis. Statistically, around $14 \%$ and $36.4 \%$ of reported cases were involved in teenager (below 20 years) and young people (21-30 years) respectively. Besides, about $26 \%$ of the reported patients in these case reports were aged between 31 to 40 years. However, the occurrence of neurovascular complication among middle aged and older people was significantly lower compared to the young and adult population with a value of $5.6 \%$ (aged between 51-60 years) and $2.80 \%$ (aged between $61-70$ years). This data clearly indicates that, young people are severely affected by neurovascular diseases as they consume cannabis in higher amount compared to older people. Although some studies have been able to establish the possible correlation between cannabis use and ischemic stroke occurrence, only $11 \%$ of total reports have demonstrated the incident of hemorrhagic stroke due to cannabis exposure (Fonseca and Ferro, 2013; Wolff and Jouanjus, 2017). Moreover, compilation of these case reports indicates that along with cannabis or cannabinoids use, other risk factors like alcohol, tobacco, dyslipidemia, migraine without aura, hypertension etc. also act as prodromal factors for the onset of cerebrovascular diseases.

Interestingly, it can also be noted from these case reports that the occurrence of neurovascular diseases such as stroke has drastically increased after 2010. Widespread availability of cannabis or synthetic cannabinoids and its legalization across the world may be the underlying reasons behind this.

\section{Population-Based Study}

Due to the alarming effect of cannabinoids on public health, several population-based studies have been performed to correlate the relation between cannabinoid exposure as well as cerebrovascular diseases. Various studies demonstrated that cannabinoids may act as a risk or prognostic factor for cerebrovascular diseases such as stroke (Westover et al., 2007; Barber et al., 2013; Hemachandra et al., 2016; Rumalla et al., 2016a; Rumalla et al., 2016b). Table 2 summarizes all the findings from population-based analysis, conducted between 2000 and 2015.

The result from these large sample size studies provide information on the temporal relationship between cannabis use and cerebrovascular complications like intracerebral hemorrhage (ICH), subarachnoid hemorrhage (SAH), and ischemic strokes (IS). Along with cannabinoids, other predominant risk factors were also considered in the assessments however, these studies have several limitations. This include lack of consideration for the high lipid solubility of cannabis metabolites which helps them to persist in fatty tissues, therefore they may be detected in the urine weeks after the initial use (Mateo et al., 2005) and this may lead to erroneous result interpretation.

\section{Probable Mechanism Associated With Cannabis-Mediated Neurovascular Diseases}

It is evident from various studies that, consumption of cannabinoids through inhalation and combustion, is associated with the occurrence of cerebral infarcts (Garrett et al., 1977; Wolff and Jouanjus, 2017). Natural cannabis and synthetic cannabinoids may act as possible trigger for reversible intracranial vasoconstriction (Wolff et al., 2015a) which along with severely reduced cerebral blood flow $(\mathrm{CBF})$ could be a major prodromal factor to neuronal death by ischemia (Wolff et al., 2014; Wolff and Jouanjus, 2017).

Different types of mechanisms might be involved in the development of stroke in cannabis users including orthostatic hypotension with the secondary impairment of the CBF autoregulation, altered cerebral vasomotor function, supine hypertension, and fluctuations in blood pressure, cardioembolism with atrial fibrillation, vasculopathy and vasospasm (Singh et al., 2012; Wolff et al., 2013; Hirapara and Aggarwal, 2016), cerebral artery luminal stenosis, increased carboxyhemoglobin level, RCVS, and angiopathy 
TABLE 1 | List of case reports related to neurovascular complications after natural and synthetic cannabinoid use (according to year; 1964-2019).

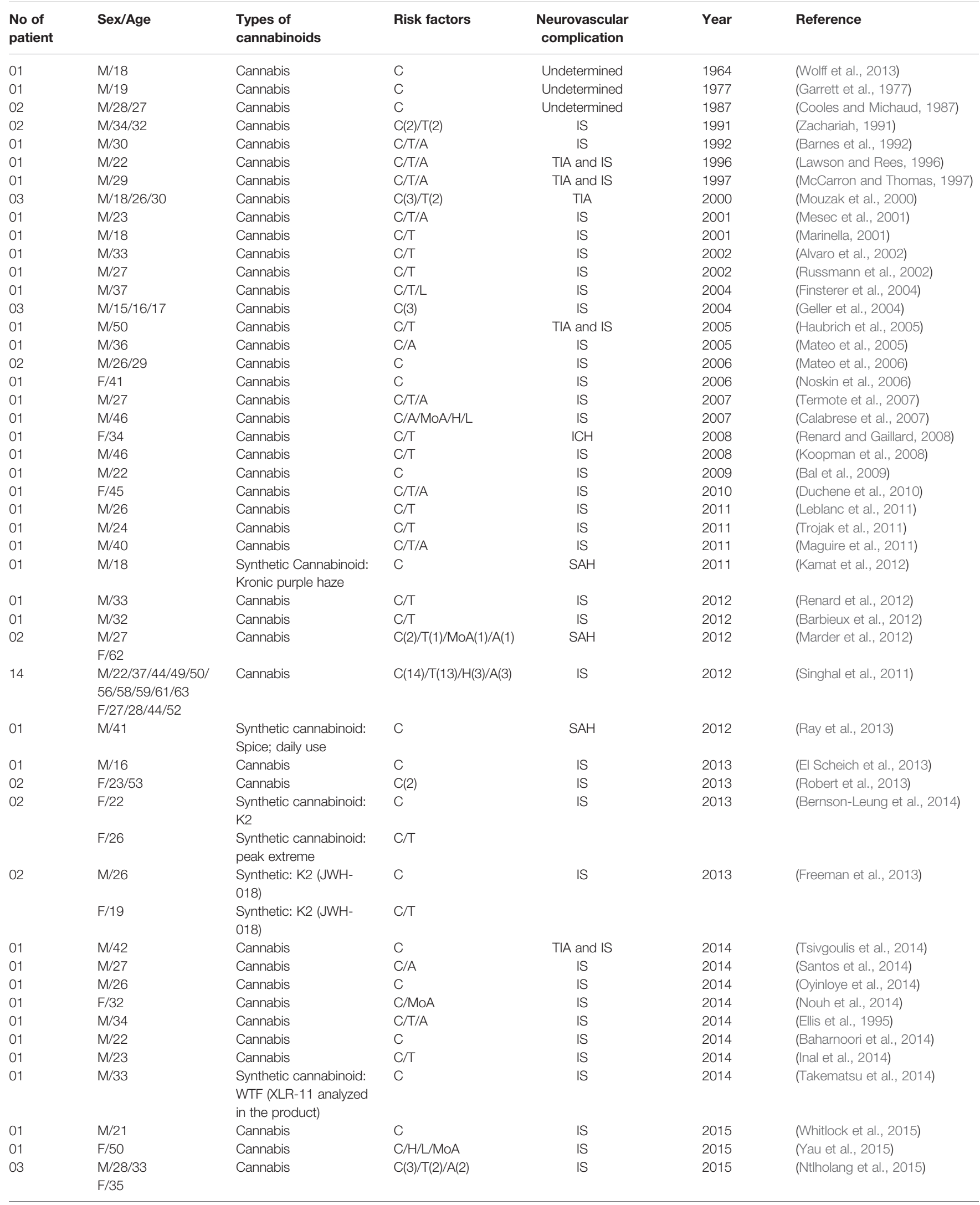


TABLE 1 | Continued

\begin{tabular}{|c|c|c|c|c|c|c|}
\hline $\begin{array}{l}\text { No of } \\
\text { patient }\end{array}$ & Sex/Age & $\begin{array}{l}\text { Types of } \\
\text { cannabinoids }\end{array}$ & Risk factors & $\begin{array}{l}\text { Neurovascular } \\
\text { complication }\end{array}$ & Year & Reference \\
\hline 01 & $M / 19$ & Cannabis & $\mathrm{C}$ & IS & 2015 & (Domi et al., 2015) \\
\hline 14 & $\begin{array}{l}\mathrm{M} / 19 / 20 / 21 / 29 / 31 / \\
36 / 37 / 38 / 44 \\
\mathrm{~F} / 21 / 24 / 26 / 31 / 33\end{array}$ & Cannabis & $\begin{array}{l}\mathrm{C}(14) / T(14) / \mathrm{MoA}(2) / \mathrm{D} \\
(4) / \mathrm{H}(3) / \mathrm{A}(5)\end{array}$ & IS & 2015 & (Wolff et al., 2015) \\
\hline 01 & $\mathrm{M} / 45$ & Synthetic cannabinoid: & $\mathrm{C} / \mathrm{T} / \mathrm{H} / \mathrm{D}$ & $\mathrm{SAH}$ & 2015 & (Sherpa et al., 2015) \\
\hline & $\mathrm{F} / 25$ & $\begin{array}{l}\text { Synthetic cannabinoid: } \\
\text { Spice (K2) + marijuana }\end{array}$ & & $\mathrm{SAH} / \mathrm{IS}$ & & \\
\hline 01 & $M / 33$ & Cannabis & $\mathrm{C} / \mathrm{T}$ & IS & 2016 & (Jamil et al., 2016) \\
\hline 01 & $M / 25$ & Cannabis & $\mathrm{C} / \mathrm{A}$ & IS & 2016 & (Tirkey and Gupta, 2016) \\
\hline 01 & $\mathrm{M} / 48$ & $\begin{array}{l}\text { Synthetic cannabinoid: } \\
\text { Chronic Bonzai }\end{array}$ & $\mathrm{C} / \mathrm{T}$ & IS & 2016 & (Degirmenci et al., 2016) \\
\hline 01 & $F / 32$ & $\begin{array}{l}\text { Synthetic cannabinoid: } \\
\text { chronic use }\end{array}$ & $\mathrm{C} / \mathrm{T}$ & IS & 2016 & $\begin{array}{l}\text { (Raheemullah and Laurence, } \\
\text { 2016) }\end{array}$ \\
\hline 01 & $M / 25$ & $\begin{array}{l}\text { Munakka or Bhang } \\
\text { tablets }\end{array}$ & $\mathrm{C} / \mathrm{A}$ & IS & 2016 & (Tirkey and Gupta, 2016) \\
\hline 01 & $M / 25$ & Cannabis joints & $\mathrm{C} / \mathrm{T} / \mathrm{A}$ & HS & 2017 & (El Mesbahy et al., 2017) \\
\hline 01 & $\mathrm{~F} / 14$ & Cannabis & $\mathrm{C} / \mathrm{A}$ & IS & 2017 & (Volpon et al., 2017) \\
\hline 01 & $F-51$ & Cannabis & C & $\mathrm{ICH}$ & 2017 & (Shere and Goyal, 2017) \\
\hline 01 & $M / 27$ & Raw cannabis & $\mathrm{C}$ & $\mathrm{ICH}$ & 2017 & (Atchaneeyasakul et al., 2017) \\
\hline 01 & $M / 37$ & Cannabis & $\mathrm{C} / \mathrm{T}$ & IS & 2018 & (Anghelescu, 2018) \\
\hline 01 & $M / 36$ & $\begin{array}{l}\text { Synthetic cannabinoid, } \\
\text { K2 }\end{array}$ & $\mathrm{C} / \mathrm{T} / \mathrm{A}$ & IS & 2018 & (Faroqui et al., 2018) \\
\hline 01 & $\mathrm{~F} / 47$ & Synthetic cannabinoid & $\mathrm{C}$ & IS & 2018 & (Jung et al., 2018) \\
\hline 01 & $M / 37$ & Marijuana & $\mathrm{C} / \mathrm{T}$ & IS & 2019 & (Sharma et al., 2019) \\
\hline
\end{tabular}

M, male; F, female; C, cannabis; SC, synthetic cannabinoids; T, tobacco; A, alcohol; L, dyslipidemia; MoA, migraine without aura; H, hypertension; FD, diabetes; IS, ischemic stroke; SAH, subarachnoid haemorrhage; ICH, intracranial haemorrhage; TIA, transient ischemic attack.

(Goyal et al., 2017). Although none of these mechanisms have been fully vetted to explain the association between use of cannabis and stroke occurrence, reversible cerebral vasoconstriction triggered by cannabis could be the most convincing theory to explain it (Wolff and Jouanjus, 2017). It was shown in different case reports that, cannabis use was associated with reversible multifocal intracranial arterial stenosis (Noskin et al., 2006; Calabrese et al., 2007; Koopman et al., 2008; Renard and Gaillard, 2008; Wolff et al., 2011; Marder et al., 2012; Tsivgoulis et al., 2014; Nouh et al., 2014; Yau et al., 2015; Wolff et al., 2015a). Along with this, another eye-catching mechanism to explain the relationship between cerebrovascular complications and cannabis use could be the cellular effect of cannabis on brain mitochondria. A recent in vivo study conducted on mice has shown that THC inhibited the complexes I, II, and III of the respiration chain of mitochondria and increased the amount of hydrogen peroxide production (Wolff et al., 2015b). This strongly suggests that ROS production and therefore, oxidative stress, could be the linking mechanism between cannabis use and stroke. This well cope with current knowledge that oxidative stress and inflammation are established prodromal factors for the onset of stroke and other neurological disorders in humans (Chen et al., 2011) (see also Figure 4).

\section{Preclinical Studies Related to the Effects of Cannabinoids and Cannabinoid Receptor on Stroke Outcome}

Different preclinical studies demonstrated the effects of cannabinoids and cannabinoid receptors on stroke outcome, One of particular interest is the fact that cannabinoids not only decreased infarct volume following an ischemic stroke (both transient and permanent occlusion models), but also improved early and late functional outcome (England et al., 2015). Furthermore activation of the endogenous cannabinoid signaling pathway as indirectly demonstrated by a study conducted on CB1 receptor knockout mice which exhibited increased mortality, severe infarct size, and neurological deficits after transient local cerebral ischemia, reduced cerebral blood flow, and increased N-methyl-d-aspartate (NMDA) neurotoxicity when compared to wild type (Parmentier-Batteur et al., 2002).

Post-stroke inflammatory responses can be reduced by CB2 ligands whereas, activation of CB1 receptors promotes chemical hypothermia. Both processes result in a reduced stroke infarct volume (Leker et al., 2003; Murikinati et al., 2010). Specifically, activation of CB1 receptor activation reduces glutamate release (Hayakawa et al., 2007), allied excitotoxicity (Shen et al., 1996) 


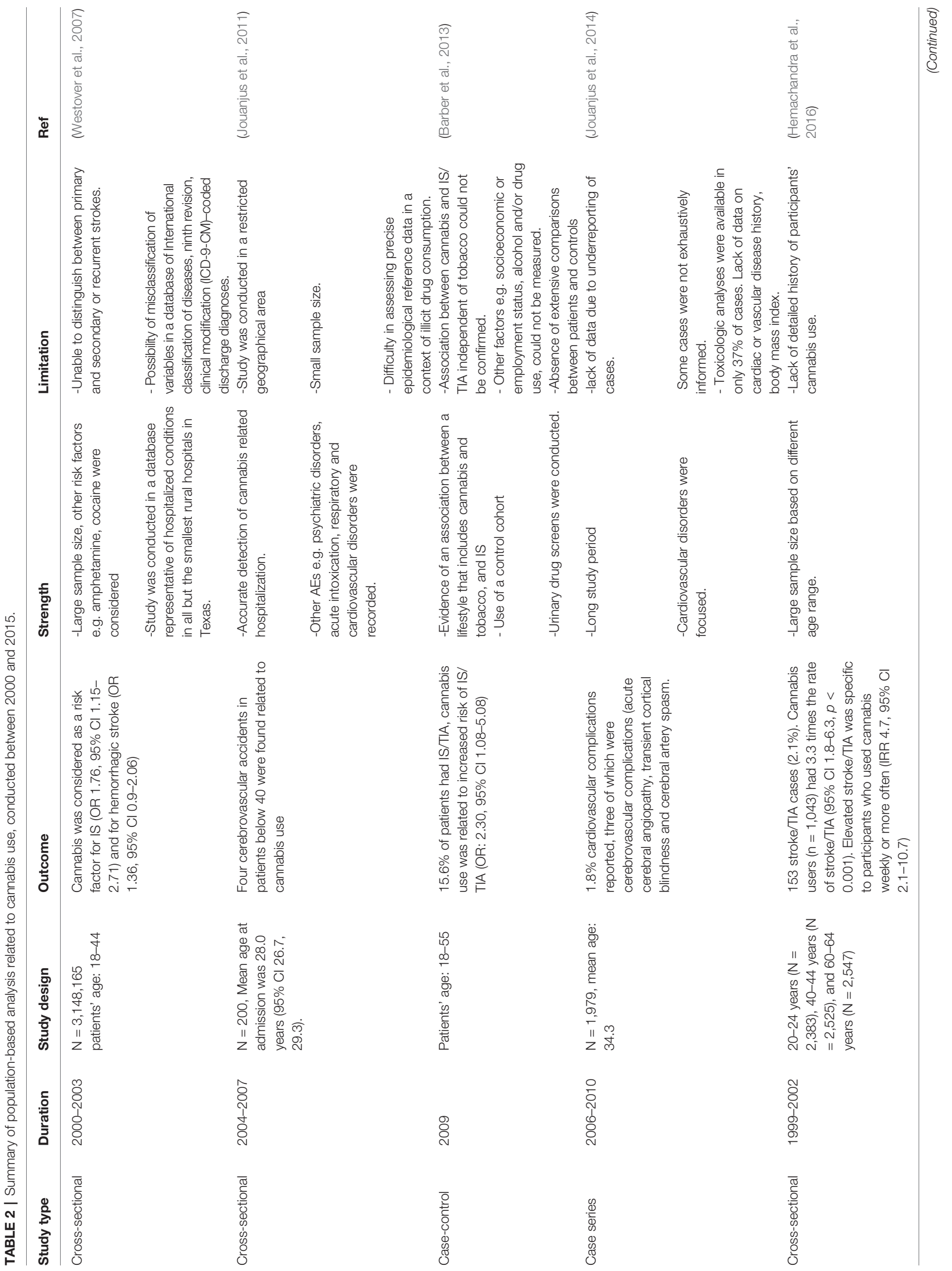




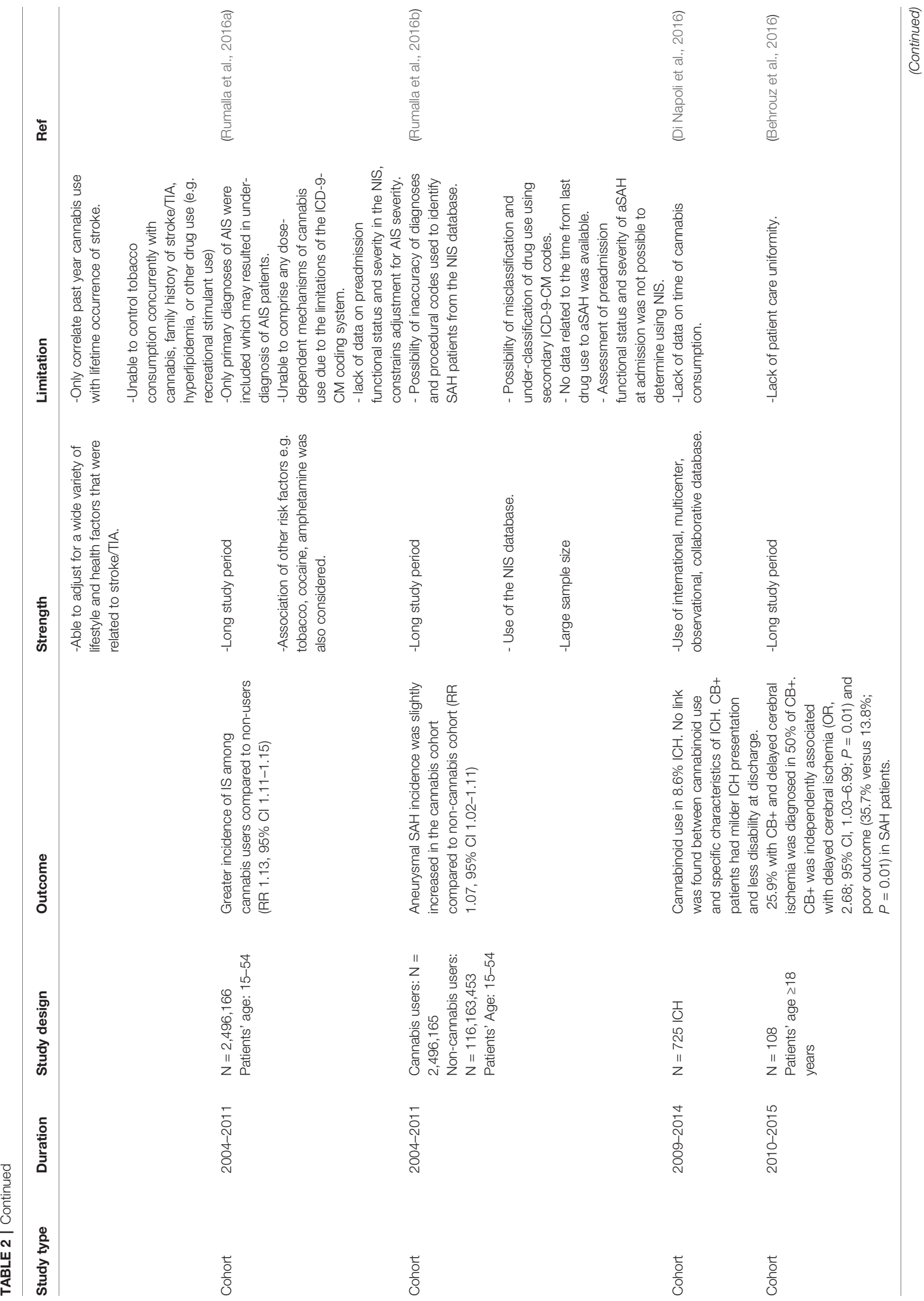




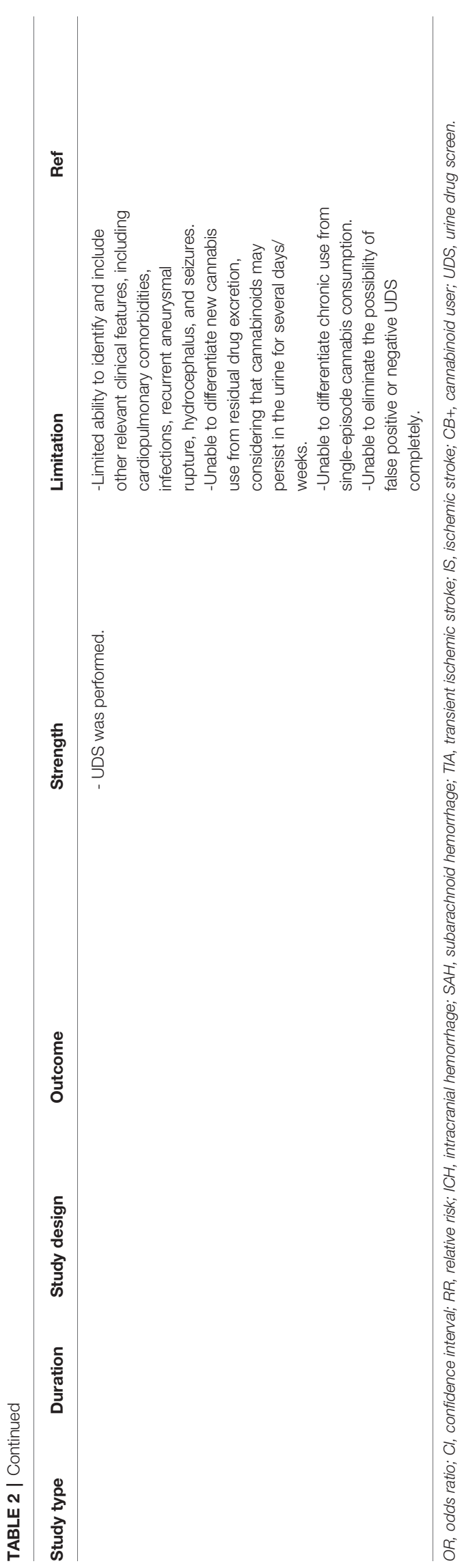

and increased cerebral blood flow (Parmentier-Batteur et al., 2002). On the other hand, CB2 receptors activation results in reduced pro-inflammatory cytokines release, neutrophil recruitment (Murikinati et al., 2010; Zarruk et al., 2012) and adhesion of leukocyte to cerebral vessels (Zhang et al., 2007).

Another study demonstrated that $\mathrm{CB} 2$ receptor plays a major role in driving neuroblast migrations as well as subsequent neurogenesis in the peri-infarct cortex after experimental stroke in mice which positively impact stroke outcome. It was also suggested that, endocannabinoid tone is essential for this process by promoting migration of neuroblasts toward the injured brain tissue which leads to increased number of new cortical neurons. As a result, motor functional recovery is increased which is beneficial for improving the outcome of aged patients as well as reducing their disabilities after chronic stroke (Bravo-Ferrer et al., 2017).

Even though these preclinical studies suggest a neuroprotective action of cannabinoids and cannabinoid receptors on stoke outcome, the matter is far from being set. In fact, conflicting results remain (Rivers-Auty et al., 2014; Garberg et al., 2016). Rivers-Auty et al. demonstrated that, CB2R agonist GW405833, cannot improve brain damage related to hypoxia-ischemia in rat models (Rivers-Auty et al., 2014). Another study conducted by Garberg HT et al. did not find any significant neuroprotective action of cannabinoids after hypoxia-ischemia in piglets (Garberg et al., 2016). Finally, most of the neuroprotective effect of cannabinoids related preclinical studies did not evaluate stroke outcomes with behavioral studies however, behavioral studies are integral part of stroke outcome research (Alamri et al., 2018). Investigators tried to correlate stroke outcomes with histological scores. Since histological improvement does not confirm long term post stroke benefits (Clarkson et al., 2010), further studies with proper behavioral outcomes is required to clarify these contradictory findings (Rivers-Auty et al., 2014). Furthermore, there are no human studies to confirm or refute these in data and properly assess the post-stroke effects of cannabinoids as neuroprotectant.

\section{Neurological Effect of Cannabis or Cannabinoids}

Cannabis based medications for instance nabiximols and THC have therapeutic potential against some symptoms associated with neurological diseases such as multiple sclerosis, chronic pain (Cohen et al., 2019). Moreover, CBD, CBDV, and $\triangle 9 \mathrm{THCV}$ have been shown to have activity against epilepsy (Scutt and Williamson, 2007; Dennis et al., 2008; Jones et al., 2010; De Petrocellis et al., 2011; Ma et al., 2008).

Exogenous cannabinoids such as CBD and nabilone are also found to have therapeutic activity in psychiatric disorders including schizophrenia, posttraumatic stress disorder (PTSD) and general and social anxiety (Cohen et al., 2019). Although cannabinoid-based drugs have shown some therapeutic activities against neurological and psychiatric disorders the effect of cannabis on the neurological system cannot be denied. It has been demonstrated from various in vivo studies that THC is responsible for inducing dose-dependent toxicity as well as 


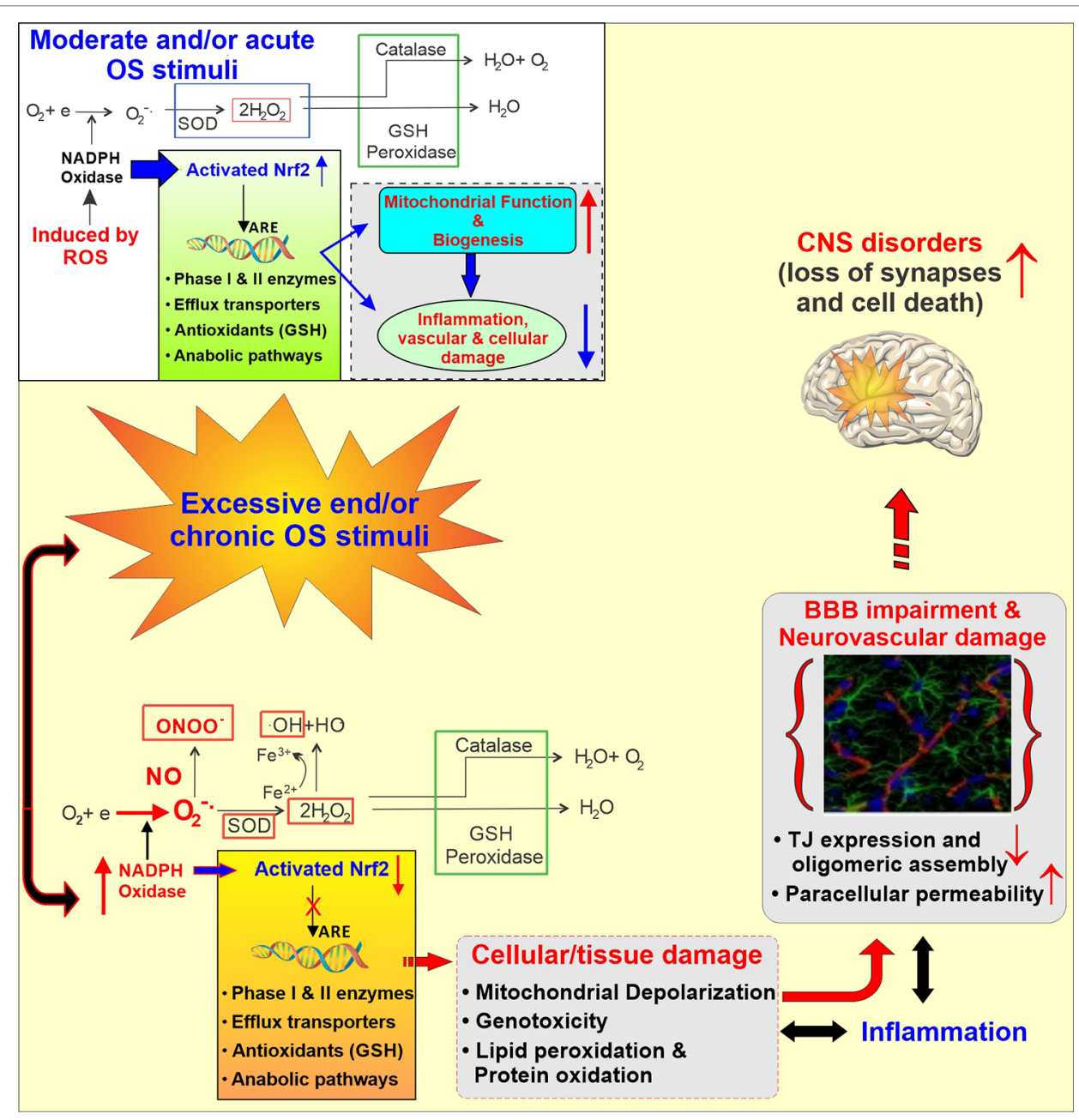

FIGURE 4 | Schematic illustration of the Activation of the cellular antioxidative response system under normal and stress condition. Under normal conditions, the response to injury is adaptive, designed to restore homoeostasis and to protect the cell from further injury. In response to excessive oxidative stress stimuli, NADPH oxidase is activated, producing an excess of $\mathrm{O}_{2}{ }^{-}$which in the presence of nitric oxide (.NO; also abundant in CS and release in response to IR) results in formation of peroxinitrite $(\mathrm{ONOO})$. Furthermore, the excess of $\mathrm{H}_{2} \mathrm{O}_{2}$ leads to the formation of hydroxyl radicals $(\mathrm{OH}$; Fenton's reaction). The unchecked OS leads then to mitochondrial depolarization, lipid peroxidation, DNA fragmentation and inflammation which at the cerebrovascular level can cause BBB damage and ultimately facilitate the onset of CNS diseases.

causing structural changes in those parts of brain which are rich in $\mathrm{CB} 1$ receptors. These receptors are located primarily in cerebellum, hippocampus, amygdala, prefrontal cortex, and striatum (Lawston et al., 2000; Downer et al., 2001; Burns et al., 2007). However, studies conducted on human brains assessing the long term cannabis use and related brain structural changes do not fully confirm these findings although changes in the density of gray or white matter have been reported in different regions of frontal and parietal lobes (Matochik et al., 2005; Churchwell et al., 2010; Gruber et al., 2011). This disconnect between in vivo and human studies might be due to the different sample characteristics, inter-individual variabilities related to past history of drug use, consumption rate, psychological problems, and differences in the experimental methodology (Batalla et al., 2013). Moreover, some studies demonstrated changes in the hippocampus/parahippocampal complex and amygdala (Matochik et al., 2005; Yucel et al., 2008; Zalesky et al., 2012; Goyal et al., 2017) and a recent one reported a significant reduction in gray matter in the $\mathrm{CB} 1$ receptors enriched regions of brain including media 1 temporal cortex, temporal pole, parahippocampal gyrus, insula, and orbitofrontal cortex when regular cannabis users were compared to groups of occasional users. These regions of the brain control motivation, emotion, and affective processing (Battistella et al., 2014). Various studies reported that, adolescents can experience persistent deficiency in different cognitive functions including attention, memory, and processing speed due to chronic cannabis use (Chadwick et al., 2013; Broyd et al., 2016; Szutorisz and Hurd, 2018). It has been found from neuropsychological tests and advanced imaging techniques that, learning process of adolescents can be affected by cannabinoid use as well (RiveraOlmos and Parra-Bernal, 2016). 
Additionally, fatal brain development can also be affected by cannabis exposure during pregnancy which may ultimately result in impaired vision and coordination, larger intermittent attention, as well as behavioral problems in children at later phase (Wu et al., 2011).

Also, different psychiatric diseases (Table 3) including schizophrenia, bipolar disorder, social anxiety, and suicidal thought are found to be higher in cannabis users compared to non-users (Mental Health, 2017).

These detrimental effects of cannabinoid may vary from person to person because of genetic variability. Besides, these detrimental effects can also depend on the age of the user. For instance, the exposure of adolescents to cannabinoids leads to severe memory impairment compared to adult (Jouroukhin et al., 2019).

Several studies have demonstrated the potential role of gene variation on the development of psychosis due to cannabis use (NIDA, 2019a). It has been found that risk of psychosis among the daily cannabis users carrying a specific variant of AK21 gene is seven times higher compared with those who use it infrequently or never used (Di Forti et al., 2012). Another study revealed an increased risk of psychosis among adults who carry a specific variant of the gene for catechol-O-methyltransferase (COMT) enzyme and used cannabis during adolescence. This enzyme can degrade different neurotransmitters for instance, dopamine and norepinephrine (Caspi et al., 2005).

Interestingly, cannabis use has also been shown to worsen the condition of schizophrenic patients. Cannabis can cause an acute psychotic reaction at high doses, in non-schizophrenic people who are cannabis users, although this fades as the drug effects wears off (NIDA, 2019a).

\section{Probable Mechanisms Associated With Cannabis Mediated Neurological Diseases}

Although the mechanism behind THC induced cognitive and behavioral dysfunction is yet to be established, recent studies conducted on mice model have demonstrated that these detrimental effects are facilitated by astrocyte CNR1 (Han et al., 2012; Chen et al., 2013). Moreover, THC may activate nuclear factor $\mathrm{\kappa B}$ signal as well as upregulate cyclooxygenase-2 (COX-2) which may result in elevated release of glutamate by astrocytes (Bezzi et al., 1998).

Interestingly, all the cannabis users do not experience cognitive impairment which clearly suggests the impact of genetic vulnerability on detrimental effects of cannabis (Blanco et al., 2016; Levine et al., 2017; Hasin, 2018). Likewise, several preclinical studies in genetically mutated mice model for psychiatric disorders showed higher effect of THC on memory (O’Tuathaigh et al., 2010; Long et al., 2013; Tantra et al., 2014; Ballinger et al., 2015; Segal-Gavish et al., 2017) although the underlying mechanism of the effect of genetic mutation on cognitive function has not been delineated yet (Jouroukhin et al., 2019). A recent study reported that genetic predisposition and THC exposure synergistically activates the NF- $\mathrm{KB}-\mathrm{COX}-2$ signal in astrocytes. This activation results in excessive glutamate secretion and decreased immunoreactivity of parvalbuminpositive presynaptic boutons around pyramidal neurons of the CA3 area of the hippocampus as well as impaired memory. It has been suggested from this research that, COX-2 inhibitors can prevent these cognitive deficits which may act as a potential target for future studies (Jouroukhin et al., 2019).

\section{Cannabis and Oxidative Stress}

It is well established that oxidative stress (OS) is associated with vascular endothelial dysfunction in a causative and dose dependent manner. Current scientific opinion considers the exposure to reactive oxygen species (ROS; e.g. $\mathrm{H}_{2} \mathrm{O}_{2}$, epoxides, nitrogen dioxide, peroxynitrite- $\mathrm{ONOO}^{-}$, etc.), and OS-mediated pathways leading to inflammation (Ahmed et al., 2019) and cellular/tissue damage to play a major role in the pathogenesis of cerebrovascular and neurological disorders like stroke, and Alzheimer's and BBB impairment (Sajja et al., 2018). At the cerebrovascular level OS promotes oxidative damage and BBB breakdown via tight junction (TJ) modification as well as activation of proinflammatory pathways (Pun et al., 2009). Under normal conditions, ROS are converted into less reactive molecules by superoxide dismutase (SOD), catalase, and glutathione peroxidase (GSH-Px) as well as scavenged by endogenous antioxidants including vitamins (such as ascorbic acid and $\alpha$-tocopherol) (Chiu et al., 2008; Hossain et al., 2011). Activation of the Nuclear factor erythroid 2-related factor (NRF2), a redox-sensitive transcription factor which, in turn, promotes the activation of several biological systems encompassing anti-inflammatory molecules, antioxidants, drug metabolizing enzymes (including cytochrome P450s), and free radical scavengers, also plays a critical protecting role against OS (136-138). However, chronic exposure to OS stimuli [such as that to tobacco smoke (Prasad et al., 2017)] can overwhelm these protective mechanisms and/or compromise their functionality (Prasad et al., 2017; Kaisar et al., 2018).

From the point of view of oxidative stress, several studies suggest that smoking marijuana is not much different than

TABLE 3 | Adverse psychiatric consequence of cannabis use (NIDA, 2019a).

Acute (present during intoxication)

Impairment of short-term memory

Impairment of cognitive functions

Impaired coordination and balance

Anxiety, paranoia

Psychosis (uncommon)
Persistent (lasting longer than intoxication, but may be temporary)

Impaired learning and coordination Sleep disorder
Long-term (total effects of repeated use)

Potential for marijuana addiction

Impairment of learning and memory with potential loss of IQ Increased risk of other drug and alcohol use disorders Increased risk of schizophrenia in people with genetic vulnerability 
smoking tobacco. Sarafian et al. have previously shown that marijuana cigarettes promote the formation of ROS while lowering the intracellular levels of glutathione (Sarafian et al., 1999). In addition, other investigators found that THC, the main psychoactive component in the cannabis, acts as a potent promoter of OS and inflammation, thus appearing as a risk factor for the onset of ischemic stroke (Wolff et al., 2015b). On the other hand, there are also evidences that non-psychoactive CBDs, can have neuroprotective effects by reducing the reactivity of microglial cells, and transmigration of leukocytes (through downregulation of chemokines, interleukin-1, and vascular cell adhesion molecule-1) (Mecha et al., 2013). In vitro studies using amyloid-beta-stimulate $\mathrm{PC} 12$ neurons $\mathrm{CBD}$ could inhibit the activity of inducible nitric oxide synthase, thus preventing the production of nitric oxide and reducing OS (Esposito et al., 2006). By contrast, in vivo studies to assess the protective effect of cannabis treatment against OS development and nigrostriatal cell injury induced by intrastriatal injection of rotenone did not produce any significant result (Omar, 2015). Unfortunately, there are contrasting results concerning the oxidative and antioxidative property of cannabinoids. Some of these controversial results could be attributed to the length of exposure such as acute vs. long term chronic exposure. As for the overall pro-oxidative effect of smoking marijuana, it is very likely that ROS are generated as a byproduct of combustion rather than a direct effect of cannabinoids. Similarly to tobacco smoke where most of the oxidative stress is generated by the combustion of tobacco rather than exposure to nicotine which can also promotes OS but to a much lower extent (Naik et al., 2014).

\section{DISCUSSION}

Cannabis or marijuana is the most widely used recreational drug and around 181 million people use it around the world ${ }^{2}$. Even though cannabis is used for treating inflammation, nausea seizure, pain, mental disorder, addiction (NIDA, 2019b) movement problem, Alzheimer's (Mack, 2000), uncontrolled use of cannabinoids may have severe detrimental effects. Nowa-days cannabis use among young people especially teenagers has been increased drastically as a recreational element. National Institute of Drug Abuse reported that, $13.90 \%$ of $8^{\text {th }}$ graders, $32.60 \%$ of $10^{\text {th }}$ graders, and $43.60 \%$ of $12^{\text {th }}$ graders are prevalent to marijuana or hashish, according to the data of 2018 (NIDA, 2018). It has also been found that, cannabis use among college students in US remains at the highest level in last three decades. Around $38 \%$ of full time college students and $41 \%$ of non-full time college students, who are aged 19-22 used cannabis at least once in one year (Schulenberg et al., 2018; Marijuana use among US college students remains at highest level in three decades, 2018). This data clearly indicates the widespread use of cannabis among youth and it is the high time to elucidate the consequence of cannabis use in human. Although the direct effect of cannabis exposure and health consequences is still unknown, numerous case reports, population-based studies as well as animal studies demonstrated the potential link between cannabis use and neurovascular as well as neurological diseases. It is evident from various studies that, recreational use of cannabinoids is related to both cardio and cerebrovascular events such as ischemic and hemorrhagic stroke (Goyal et al., 2017) and neurological diseases for instance structural and functional changes in brain, cognitive dysfunction as well as behavioral disorders (Chadwick et al., 2013; Battistella et al., 2014; Broyd et al., 2016; Szutorisz and Hurd, 2018). Unfortunately, both cerebrovascular and neurological disorders are found to be higher in young population as they are the main consumer.

Although the underlying mechanism behind cannabis use and occurrence of cerebrovascular diseases has not been elucidated yet, the handful of case reports and preclinical studies on animal model highlighted provide some plausible insights. These includes (but not limited to) reversible cerebral vasoconstriction (Wolff et al., 2015a), ROS generation inducing oxidative stress (although, similar to tobacco smoke ROS could be generated as a byproduct of marijuana combustion rather than a specific effect of cannabinoids) (Chen et al., 2011), cerebral artery luminal stenosis, cerebral auto-dysregulation, cardioembolism, reversible cerebral vasoconstriction syndrome (RCVS), angiopathy (Goyal et al., 2017). A very recent report showed that, genetic modifications as well as age of consumers play a pivotal role in developing neurological disorders (Jouroukhin et al., 2019). However, additional and more specific studies will be necessary to determine their relevant contribution to the onset of cerebrovascular and neurological disorders.

To the best of our knowledge, a very few studies have been performed to understand the mechanism of detrimental effect of cannabis on both neurology and the BBB. Since the BBB restricts the communication between blood and brain parenchyma and maintains cerebral homeostasis, damage of $\mathrm{BBB}$ results in neuronal dysregulation and degeneration. Therefore, it is evident the studying the effects of cannabis and particularly chronic exposure to it, should be considered a major target for future studies.

\section{AUTHOR CONTRIBUTIONS}

SA conceived the study and prepared the drafting of the manuscript. LC assisted with the drafting of the manuscript and preparation of the figures. LC also oversaw the entire project and provided funding support. All authors reviewed the manuscript.

\section{FUNDING}

This work was supported by the National Institutes of Health/ National Institute on Drug Abuse 2R01-DA029121-01A1 and National Institutes of Health/Food and Drug Administration 1R01-OD026234 to LC. 


\section{REFERENCES}

Abbott, N. J., and Friedman, A. (2012). Overview and introduction: the bloodbrain barrier in health and disease. Epilepsia 53 Suppl 6, 1-6. doi: 10.1111/ j.1528-1167.2012.03696.x

Abbott, N. J., Patabendige, A. A., Dolman, D. E., Yusof, S. R., and Begley, D. J. (2010). Structure and function of the blood-brain barrier. Neurobiol. Dis. 37, 13-25. doi: 10.1016/j.nbd.2009.07.030

Abbott, N. J. (2013). Blood-brain barrier structure and function and the challenges for CNS drug delivery. J. Inherit. Metab. Dis. 36, 437-449. doi: 10.1007/s10545013-9608-0

Abdullahi, W., Tripathi, D., and Ronaldson, P. T. (2018). Blood-brain barrier dysfunction in ischemic stroke: targeting tight junctions and transporters for vascular protection. Am. J. Physiol. Cell Physiol. 315, C343-C356. doi: 10.1152/ ajpcell.00095.2018

Adams, I. B., and Martin, B. R. (1996). Cannabis: pharmacology and toxicology in animals and humans. Addiction 91, 1585-1614 doi: 10.1046/j.1360-0443.1996. 911115852.x

Ahmed, T., Archie, S. R., Faruk, A., Chowdhury, F. A., Al Shoyaib, A., Ahsan, C. R., et al. (2019). Evaluation of the anti-inflammatory activities of diclofenac sodium, prednisolone and atorvastatin in combination with ascorbic acid. Antiinflamm. Antiallergy Agents Med. Chem. 18, 1. doi: 10.2174/ 1871523018666190514112048

Alamri, F. F., Shoyaib, A. A., Biggers, A., Jayaraman, S., Guindon, J., and Karamyan, V. T. (2018). Applicability of the grip strength and automated von Frey tactile sensitivity tests in the mouse photothrombotic model of stroke. Behav. Brain Res. 336, 250-255. doi: 10.1016/j.bbr.2017.09.008

Alvaro, L. C., Iriondo, I., and Villaverde, F. J. (2002). Sexual headache and stroke in a heavy cannabis smoker. Headache 42, 224-226. doi: 10.1046/j.1526-4610. 2002.02056.x

Anghelescu, A. (2018). Uncommon association of two anatomical variants of cerebral circulation: a fetal-type posterior cerebral artery and inferred artery of percheron, complicated with paramedian thalamomesencephalic stroke-case presentation and literature review. Case Rep. Neurol. Med. 2018, 9. doi: $10.1155 / 2018 / 4567206$

Ashton, C. H. (2001). Pharmacology and effects of cannabis: a brief review. Br. J. Psychiatry 178, 101-106. doi: 10.1192/bjp.178.2.101

Atakan, Z. (2012). Cannabis, a complex plant: different compounds and different effects on individuals. Ther. Adv. Psychopharmacol. 2, 241-254. doi: 10.1177/ 2045125312457586

Atchaneeyasakul, K., Torres, L. F., and Malik, A. M. (2017). Large amount of cannabis ingestion resulting in spontaneous intracerebral hemorrhage: a case report. J. Stroke Cerebrovasc. Dis. 26, e138-e139. doi: 10.1016/ j.jstrokecerebrovasdis.2017.04.017

Baharnoori, M., Kassardjian, C. D., and Saposnik, G. (2014). Cannabis use associated with capsular warning syndrome and ischemic stroke. Can. J. Neurol. Sci. 41, 272-273. doi: 10.1017/s0317167100016711

Bal, S., Khurana, D., Lal, V., and Prabhakar, S. (2009). Posterior circulation stroke in a cannabis abuser. Neurol. India 57, 91-92. doi: 10.4103/0028-3886.48797

Ballinger, M. D., Saito, A., Abazyan, B., Taniguchi, Y., Huang, C. H., Ito, K., et al. (2015). Adolescent cannabis exposure interacts with mutant DISC1 to produce impaired adult emotional memory. Neurobiol. Dis. 82, 176-184. doi: 10.1016/ j.nbd.2015.06.006

Barber, P. A., Pridmore, H. M., Krishnamurthy, V., Roberts, S., Spriggs, D. A., and Carter, K. N. (2013). Cannabis, ischemic stroke, and transient ischemic attack: a case-control study. Stroke 44, 2327-2329. doi: 10.1161/STROKEAHA. 113.001562

Barbieux, M., Veran, O., and Detante, O. (2012). Ischemic strokes in young adults and illegal drugs. Rev. Med. Intern. 33, 35-40. doi: 10.1016/j.revmed.2011.04.008

Barnes, D., Palace, J., and O’Brien, M. D. (1992). Stroke following marijuana smoking. Stroke 23, 1381. doi: 10.1161/01.str.23.9.1381

Batalla, A., Bhattacharyya, S., Yucel, M., Fusar-Poli, P., Crippa, J. A., Nogue, S., et al. (2013). Structural and functional imaging studies in chronic cannabis users: a systematic review of adolescent and adult findings. PloS One 8, e55821. doi: 10.1371/journal.pone.0055821

Battistella, G., Fornari, E., Annoni, J. M., Chtioui, H., Dao, K., Fabritius, M., et al. (2014). Long-term effects of cannabis on brain structure. Neuropsychopharmacology 39, 2041-2048. doi: 10.1038/npp.2014.67
Behrouz, R., Birnbaum, L., Grandhi, R., Johnson, J., Misra, V., Palacio, S., et al. (2016). Cannabis use and outcomes in patients with aneurysmal subarachnoid hemorrhage. Stroke 47, 1371-1373. doi: 10.1161/STROKEAHA.116.013099

Bernson-Leung, M. E., Leung, L. Y., and Kumar, S. (2014). Synthetic cannabis and acute ischemic stroke. J. Stroke Cerebrovasc. Dis. 23, 1239-1241. doi: 10.1016/ j.jstrokecerebrovasdis.2013.07.030

Bezzi, P., Carmignoto, G., Pasti, L., Vesce, S., Rossi, D., Rizzini, B. L., et al. (1998). Prostaglandins stimulate calcium-dependent glutamate release in astrocytes. Nature 391, 281-285. doi: 10.1038/34651

Blanco, C., Hasin, D. S., Wall, M. M., Florez-Salamanca, L., Hoertel, N., Wang, S., et al. (2016). Cannabis use and risk of psychiatric disorders: prospective evidence from a US national longitudinal study. JAMA Psychiatry 73, 388395. doi: 10.1001/jamapsychiatry.2015.3229

Bloom, A. S., Tershner, S., Fuller, S. A., and Stein, E. A. (1997). Cannabinoidinduced alterations in regional cerebral blood flow in the rat. Pharmacol. Biochem. Behav. 57, 625-631. doi: 10.1016/s0091-3057(96)00475-3

Booth, J. K., Page, J. E., and Bohlmann, J. (2017). Terpene synthases from Cannabis sativa. PloS One 12, e0173911. doi: 10.1371/journal.pone.0173911

Bravo-Ferrer, I., Cuartero, M. I., Zarruk, J. G., Pradillo, J. M., Hurtado, O., Romera, V. G., et al. (2017). Cannabinoid type-2 receptor drives neurogenesis and improves functional outcome after stroke. Stroke 48, 204-212. doi: 10.1161/ STROKEAHA.116.014793

Broyd, S. J., van Hell, H. H., Beale, C., Yucel, M., and Solowij, N. (2016). Acute and chronic effects of cannabinoids on human cognition-a systematic review. Biol. Psychiatry 79, 557-567. doi: 10.1016/j.biopsych.2015.12.002

Burns, H. D., Van Laere, K., Sanabria-Bohorquez, S., Hamill, T. G, Bormans, G., Eng, W. S., et al. (2007). [18F]MK-9470, a positron emission tomography (PET) tracer for in vivo human PET brain imaging of the cannabinoid-1 receptor. Proc. Natl. Acad. Sci. U.S.A. 104, 9800-9805. doi: 10.1073/pnas.0703472104

Calabrese, L. H., Dodick, D. W., Schwedt, T. J., and Singhal, A. B. (2007). Narrative review: reversible cerebral vasoconstriction syndromes. Ann. Intern. Med. 146, 34-44. doi: 10.7326/0003-4819-146-1-200701020-00007

Caspi, A., Moffitt, T. E., Cannon, M., McClay, J., Murray, R., Harrington, H., et al. (2005). Moderation of the effect of adolescent-onset cannabis use on adult psychosis by a functional polymorphism in the catechol-O-methyltransferase gene: longitudinal evidence of a gene $\mathrm{X}$ environment interaction. Biol. Psychiatry 57, 1117-1127. doi: 10.1016/j.biopsych.2005.01.026

Chadwick, B., Miller, M. L., and Hurd, Y. L. (2013). Cannabis use during adolescent development: susceptibility to psychiatric illness. Front. Psychiatry 4, 129. doi: 10.3389/fpsyt.2013.00129

Chen, H., Yoshioka, H., Kim, G. S., Jung, J. E., Okami, N., Sakata, H., et al. (2011). Oxidative stress in ischemic brain damage: mechanisms of cell death and potential molecular targets for neuroprotection. Antioxid. Redox Signal 14, 1505-1517. doi: 10.1089/ars.2010.3576

Chen, R., Zhang, J., Fan, N., Teng, Z. Q., Wu, Y., Yang, H., et al. (2013). Delta9THC-caused synaptic and memory impairments are mediated through COX-2 signaling. Cell 155, 1154-1165. doi: 10.1016/j.cell.2013.10.042

Chiarotti, M., and Costamagna, L. (2000). Analysis of 11-nor-9-carboxy-delta(9)tetrahydrocannabinol in biological samples by gas chromatography tandem mass spectrometry (GC/MS-MS). Forensic Sci. Int. 114, 1-6. doi: 10.1016/ s0379-0738(00)00248-6

Chiu, H. J., Fischman, D. A., and Hammerling, U. (2008). Vitamin A depletion causes oxidative stress, mitochondrial dysfunction, and PARP-1-dependent energy deprivation. FASEB J. 22, 3878-3887. doi: 10.1096/fj.08-112375

Churchwell, J. C., Lopez-Larson, M., and Yurgelun-Todd, D. A. (2010). Altered frontal cortical volume and decision making in adolescent cannabis users. Front. Psychol. 1, 225. doi: 10.3389/fpsyg.2010.00225

Clarkson, A. N., Huang, B. S., Macisaac, S. E., Mody, I., and Carmichael, S. T. (2010). Reducing excessive GABA-mediated tonic inhibition promotes functional recovery after stroke. Nature 468, 305-309. doi: 10.1038/ nature 09511

Cohen, K., Weizman, A., and Weinstein, A. (2019). Positive and negative effects of cannabis and cannabinoids on health. Clin. Pharmacol. Ther. 105, 1139-1147. doi: 10.1002/cpt.1381

Console-Bram, L., Brailoiu, E., Brailoiu, G. C., Shahir, H., and Abood, M. E. (2014). Activation of GPR18 by cannabinoid compounds: a tale of biased agonism. Br. J. Pharmacol. 171, 3908-3917. doi: 10.1111/bph.12746 
Cooles, P., and Michaud, R. (1987). Stroke after heavy cannabis smoking. Postgrad Med. J. 63, 511. doi: 10.1136/pgmj.63.740.511

Crepault, J. F. (2018). Cannabis legalization in canada: reflections on public health and the governance of legal psychoactive substances. Front. Public Health 6, 220. doi: $10.3389 /$ fpubh.2018.00220

Daneman, R., and Prat, A. (2015). The blood-brain barrier. Cold Spring Harb. Perspect. Biol. 7. doi: 10.1101/cshperspect.a020412

De Petrocellis, L., Ligresti, A., Moriello, A. S., Allara, M., Bisogno, T., Petrosino, S., et al. (2011). Effects of cannabinoids and cannabinoid-enriched Cannabis extracts on TRP channels and endocannabinoid metabolic enzymes. Br. J. Pharmacol. 163, 1479-1494. doi: 10.1111/j.1476-5381.2010.01166.x

Degirmenci, Y., Kececi, H., and Olmez, N. (2016). A case of ischemic stroke after bonzai: syntetic cannabinoid from Turkey. Neurol. Sci. 37, 299-300. doi: 10.1007/s10072-015-2397-5

Demirakca, T., Sartorius, A., Ende, G., Meyer, N., Welzel, H., Skopp, G., et al. (2011). Diminished gray matter in the hippocampus of cannabis users: possible protective effects of cannabidiol. Drug Alcohol Depend. 114, 242-245. doi: 10.1016/j.drugalcdep.2010.09.020

Dennis, I., Whalley, B. J., and Stephens, G. J. (2008). Effects of Delta9tetrahydrocannabivarin on [35S]GTPgammaS binding in mouse brain cerebellum and piriform cortex membranes. Br. J. Pharmacol. 154, 13491358. doi: 10.1038/bjp.2008.190

Di Forti, M., Iyegbe, C., Sallis, H., Kolliakou, A., Falcone, M. A., Paparelli, A, et al. (2012). Confirmation that the AKT1 (rs2494732) genotype influences the risk of psychosis in cannabis users. Biol. Psychiatry 72, 811-816. doi: 10.1016/ j.biopsych.2012.06.020

Di Napoli, M., Zha, A. M., Godoy, D. A., Masotti, L., Schreuder, F. H., Popa-Wagner, A., et al. (2016). Prior cannabis use is associated with outcome after intracerebral hemorrhage. Cerebrovasc. Dis. 41, 248-255. doi: 10.1159/000443532

Domi, R., Janko, A., and Sula, H. (2015). An unusual postoperative cerebral ischemic stroke. J. Anesth. 29, 157. doi: 10.1007/s00540-014-1874-y

Downer, E., Boland, B., Fogarty, M., and Campbell, V. (2001). Delta 9tetrahydrocannabinol induces the apoptotic pathway in cultured cortical neurones via activation of the CB1 receptor. Neuroreport 12, 3973-3978. doi: 10.1097/00001756-200112210-00024

Duchene, C., Olindo, S., Chausson, N., Jeannin, S., Cohen-Tenoudji, P., Smadja, D., et al. (2010). Cannabis-induced cerebral and myocardial infarction in a young woman. Rev. Neurol. (Paris) 166, 438-442. doi: 10.1016/j.neurol.2009.10.006

El Mesbahy, J., Chraa, M., Louhab, N., and Kissani, N. (2017). Hemorrhagic stroke after cannabis use in a young man. Rev. Neurol. (Paris) 173, 666-668. doi: 10.1016/j.neurol.2017.05.002

El Scheich, T., Weber, A. A., Klee, D., Schweiger, D., Mayatepek, E., Karenfort, M., et al. (2013). Adolescent ischemic stroke associated with anabolic steroid and cannabis abuse. J. Pediatr. Endocrinol. Metab. 26, 161-165. doi: 10.1515/jpem2012-0057

Ellis, E. F., Moore, S. F., and Willoughby, K. A. (1995). Anandamide and delta 9THC dilation of cerebral arterioles is blocked by indomethacin. Am. J. Physiol. 269, H1859-H1864. doi: 10.1152/ajpheart.1995.269.6.H1859

England, T. J., Hind, W. H., Rasid, N. A., and O'Sullivan, S. E. (2015). Cannabinoids in experimental stroke: a systematic review and meta-analysis. J. Cereb. Blood Flow Metab. 35, 348-358. doi: 10.1038/jcbfm.2014.218

Esposito, G., De Filippis, D., Maiuri, M. C., De Stefano, D., Carnuccio, R., Iuvone, T., et al. (2006). Cannabidiol inhibits inducible nitric oxide synthase protein expression and nitric oxide production in beta-amyloid stimulated PC12 neurons through p38 MAP kinase and NF-kappaB involvement. Neurosci. Lett. 399, 91-95. doi: 10.1016/j.neulet.2006.01.047

Faroqui, R., Mena, P., Wolfe, A. R., Bibawy, J., Visvikis, G. A., Mantello, M. T., et al. (2018). Acute carotid thrombosis and ischemic stroke following overdose of the synthetic cannabinoid K2 in a previously healthy young adult male. Radiol. Case Rep. 13, 747-752. doi: 10.1016/j.radcr.2018.02.023

Finsterer, J., Christian, P., and Wolfgang, K. (2004). Occipital stroke shortly after cannabis consumption. Clin. Neurol. Neurosurg. 106, 305-308. doi: 10.1016/ j.clineuro.2004.02.001

Fonseca, A. C., and Ferro, J. M. (2013). Drug abuse and stroke. Curr. Neurol. Neurosci. Rep. 13, 325. doi: 10.1007/s11910-012-0325-0

Ford, T. C., Hayley, A. C., Downey, L. A., and Parrott, A. C. (2017). Cannabis: an overview of its adverse acute and chronic effects and its implications. Curr. Drug Abuse Rev. 10, 6-18. doi: 10.2174/1874473710666170712113042
Freeman, M. J., Rose, D. Z., Myers, M. A., Gooch, C. L, C. L., Bozeman, A. C., and Burgin, W. S. (2013). Ischemic stroke after use of the synthetic marijuana “spice". Neurology 81, 2090-2093. doi: 10.1212/01.wnl.0000437297.05570.a2

Gaoni Y and Mechoulam, R. (1964). Isolation, structure, and partial synthesis of an active constituent of hashish. J. Am. Chem. Soc. 86, 1646-1647. doi: 10.1021/ ja01062a046

Garberg, H. T., Huun, M. U., Escobar, J., Martinez-Orgado, J., Loberg, E. M., Solberg, I., et al. (2016). Short-term effects of cannabidiol after global hypoxiaischemia in newborn piglets. Pediatr. Res. 80, 710-718. doi: 10.1038/ pr.2016.149

Garrett, C. P., Braithwaite, R. A., and Teale, J. D. (1977). Unusual case of tetrahydrocannabinol intoxication confirmed by radioimmunoassay. $\mathrm{Br}$. Med. J. 2, 166. doi: 10.1136/bmj.2.6080.166

Gebremedhin, D., Lange, A. R., Campbell, W. B., Hillard, C. J., and Harder, D. R. (1999). Cannabinoid CB1 receptor of cat cerebral arterial muscle functions to inhibit L-type Ca2+ channel current. Am. J. Physiol. 276, H2085-H2093. doi: 10.1152/ajpheart.1999.276.6.H2085

Geller, T., Loftis, L., and Brink, D. S. (2004). Cerebellar infarction in adolescent males associated with acute marijuana use. Pediatrics 113, e365-e370. doi: 10.1542/peds.113.4.e365

Goyal, H., Awad, H. H., and Ghali, J. K. (2017). Role of cannabis in cardiovascular disorders. J. Thorac. Dis. 9, 2079-2092. doi: 10.21037/jtd.2017.06.104

Grotenhermen, F. (2005). Cannabinoids. Curr. Drug Targets CNS Neurol. Disord. 4, 507-530. doi: 10.2174/156800705774322111

Gruber, S. A., Silveri, M. M., Dahlgren, M. K., and Yurgelun-Todd, D. (2011). Why so impulsive? White matter alterations are associated with impulsivity in chronic marijuana smokers. Exp. Clin. Psychopharmacol. 19, 231-242. doi: $10.1037 / \mathrm{a} 0023034$

Gurney, S. M., Scott, K. S., Kacinko, S. L., Presley, B. C., and Logan, B. K. (2014). Pharmacology, toxicology, and adverse effects of synthetic cannabinoid drugs. Forensic Sci. Rev. 26, 53-78.

Hall, W., and Degenhardt, L. (2009). Adverse health effects of non-medical cannabis use. Lancet 374, 1383-1391. doi: 10.1016/S0140-6736(09)61037-0

Han, J., Kesner, P., Metna-Laurent, M., Duan, T., Xu, L., Georges, F., et al. (2012). Acute cannabinoids impair working memory through astroglial CB1 receptor modulation of hippocampal LTD. Cell 148, 1039-1050. doi: 10.1016/ j.cell.2012.01.037

Hasin, D. S. (2018). US epidemiology of cannabis use and associated problems. Neuropsychopharmacology 43, 195-212. doi: 10.1038/npp.2017.198

Haubrich, C., Diehl, R., Donges, M., Schiefer, J., Loos, M., and Kosinki, C. (2005). Recurrent transient ischemic attacks in a cannabis smoker. J. Neurol. 252, 369370. doi: 10.1007/s00415-005-0650-1

Hayakawa, K., Mishima, K., Nozako, M., Hazekawa, M., Irie, K., Fujioka, M., et al. (2007). Delayed treatment with cannabidiol has a cerebroprotective action via a cannabinoid receptor-independent myeloperoxidase-inhibiting mechanism. J. Neurochem. 102, 1488-1496. doi: 10.1111/j.1471-4159.2007.04565.x

Hemachandra, D., McKetin, R., Cherbuin, N., and Anstey, K. J. (2016). Heavy cannabis users at elevated risk of stroke: evidence from a general population survey. Aust. N. Z. J. Public Health 40, 226-230. doi: 10.1111/1753-6405.12477

Hendricks, B. K., Hartman, J., and Cohen-Gadol, A. A. (2018). Cerebrovascular operative anatomy: an immersive $3 \mathrm{D}$ and virtual reality description. Oper. Neurosurg. (Hagerstown) 15, 613-623. doi: 10.1093/ons/opy283

Herkenham, M., Lynn, A. B., Little, M. D., Johnson, M. R., Melvin, L. S., de Costa, B. R., et al. (1990). Cannabinoid receptor localization in brain. Proc. Natl. Acad. Sci. U.S.A. 87, 1932-1936. doi: 10.1073/pnas.87.5.1932

Hillard, C. J., Ho, W. S., Thompson, J., Gauthier, K. M., Wheelock, C. E., Huang, H., et al. (2007). Inhibition of 2-arachidonoylglycerol catabolism modulates vasoconstriction of rat middle cerebral artery by the thromboxane mimetic,U-46619. Br. J. Pharmacol. 152, 691-698. doi: 10.1038/sj.bjp.0707468

Hirapara, K., and Aggarwal, R. (2016). Synthetic cannabis use and stroke: a rising risk? Int. J. Stroke 11, NP78. doi: 10.1177/1747493016641956

Hollister, L. E., Gillespie, H. K., Ohlsson, A., Lindgren, J. E., Wahlen, A., and Agurell, S. (1981). Do plasma concentrations of delta 9-tetrahydrocannabinol reflect the degree of intoxication? J. Clin. Pharmacol. 21, 171S-177S. doi: 10.1002/j.15524604.1981.tb02593.x

Hossain, M., Mazzone, P., Tierney, W., and Cucullo, L. (2011). In vitro assessment of tobacco smoke toxicity at the BBB: do antioxidant supplements have a protective role? BMC Neurosci. 12, 92. doi: 10.1186/1471-2202-12-92 
Inal, T., Kose, A., Koksal, O., Armagan, E., Aydin, S. A., and Ozdemir, F. (2014). Acute temporal lobe infarction in a young patient associated with marijuana abuse: an unusual cause of stroke. World J. Emerg. Med. 5, 72-74. doi: 10.5847/ wjem.j.1920-8642.2014.01.013

Ince, B., Benbir, G., Yuksel, O., Koseoglu, L., and Uluduz, D. (2015). Both hemorrhagic and ischemic stroke following high doses of cannabis consumption. Presse Med. 44, 106-107. doi: 10.1016/j.lpm.2014.05.022

Iring, A., Ruisanchez, E., Leszl-Ishiguro, M., Horvath, B., Benko, R., Lacza, Z., et al. (2013). Role of endocannabinoids and cannabinoid-1 receptors in cerebrocortical blood flow regulation. PloS One 8, e53390. doi: 10.1371/ journal.pone.0053390

Jamil, M., Zafar, A., Adeel Faizi, S., and Zawar, I. (2016). Stroke from vasospasm due to marijuana use: can cannabis synergistically with other medications trigger cerebral vasospasm? Case Rep. Neurol. Med. 2016, 5313795. doi: $10.1155 / 2016 / 5313795$

Jones, N. A., Hill, A. J., Smith, I., Bevan, S. A., Williams, C. M., Whalley, B. J., et al. (2010). Cannabidiol displays antiepileptiform and antiseizure properties in vitro and in vivo. J. Pharmacol. Exp. Ther. 332, 569-577. doi: 10.1124/jpet.109.159145

Jouanjus, E., Leymarie, F., Tubery, M., and Lapeyre-Mestre, M. (2011). Cannabisrelated hospitalizations: unexpected serious events identified through hospital databases. Br. J. Clin. Pharmacol. 71, 758-765. doi: 10.1111/j.13652125.2010.03897.x

Jouanjus, E., Lapeyre-Mestre, M., Micallef, J., French Association of the Regional, A., and Dependence Monitoring Centres Working Group on Cannabis, C. (2014). Cannabis use: signal of increasing risk of serious cardiovascular disorders. J. Am. Heart Assoc. 3, e000638. doi: 10.1161/JAHA.113.000638

Jouroukhin, Y., Zhu, X., Shevelkin, A. V., Hasegawa, Y., Abazyan, B., Saito, A., et al. (2019). Adolescent delta(9)-tetrahydrocannabinol exposure and astrocyte-specific genetic vulnerability converge on nuclear factor-kappaBcyclooxygenase-2 signaling to impair memory in adulthood. Biol. Psychiatry 85, 891-903. doi: 10.1016/j.biopsych.2018.07.024

Jung, J. S., Park, Y. W., Lee, S. A., Song, T. J., and Lim, S. M. (2018). Ischemic Stroke after Use of Cannabis: a Case Report and Review of Literature. Investig. Magn. Reson. Imaging 22, 168-171. doi: 10.13104/imri.2018.22.3.168

Kaisar, M. A., Sajja, R. K., Prasad, S., Abhyankar, V. V., Liles, T., and Cucullo, L. (2017). New experimental models of the blood-brain barrier for CNS drug discovery. Expert Opin. Drug Discovery 12, 89-103. doi: 10.1080/17460441. 2017.1253676

Kaisar, M. A., Sivandzade, F., Bhalerao, A., and Cucullo, L. (2018). Conventional and electronic cigarettes dysregulate the expression of iron transporters and detoxifying enzymes at the brain vascular endothelium: in vivo evidence of a gender-specific cellular response to chronic cigarette smoke exposure. Neurosci. Lett. 682, 1-9. doi: 10.1016/j.neulet.2018.05.045

Kamat, A. S., Aliashkevich, A. F., Denton, J. R., and Fitzjohn, T. P. (2012). Headache after substance abuse: a diagnostic dilemma. J. Clin. Neurosci. 19, 464-466. doi: 10.1016/j.jocn.2011.07.028

Karila, L., Roux, P., Rolland, B., Benyamina, A., Reynaud, M., Aubin, H. J., et al. (2014). Acute and long-term effects of cannabis use: a review. Curr. Pharm. Des. 20, 4112-4118. doi: 10.2174/13816128113199990620

Keskin, M., Hayiroglu, M. I., Keskin, U., and Eren, M. (2016). Acute myocardial infarction and ischemic stroke coexistence due to marijuana abuse in an adolescent. Anatol. J. Cardiol. 16, 542-543. doi: 10.14744/ AnatolJCardiol.2016.6978

Koopman, K., Teune, L. K., ter Laan, M., Uyttenboogaart, M., Vroomen, P. C., and De Keyser, J. (2008). An often unrecognized cause of thunderclap headache: reversible cerebral vasoconstriction syndrome. J. Headache Pain 9, 389-391. doi: 10.1007/s10194-008-0068-0

Lawson, T. M., and Rees, A. (1996). Stroke and transient ischaemic attacks in association with substance abuse in a young man. Postgrad Med. J. 72, 692-693. doi: $10.1136 /$ pgmj.72.853.692

Lawston, J., Borella, A., Robinson, J. K., and Whitaker-Azmitia, P. M. (2000). Changes in hippocampal morphology following chronic treatment with the synthetic cannabinoid WIN 55,212-2. Brain Res. 877, 407-410. doi: 10.1016/ s0006-8993(00)02739-6

Leblanc, A., Tirel-Badets, A., Paleiron, N., Castellant, P., Cornilly, J. C., Andre, M., et al. (2011). Cannabis and myocardial infarction without angiographic stenosis in young patient: guilty or not guilty? A case report. Ann. Cardiol. Angeiol (Paris) 60, 154-158. doi: 10.1016/j.ancard.2010.12.018
Leker, R. R., Gai, N., Mechoulam, R., and Ovadia, H. (2003). Drug-induced hypothermia reduces ischemic damage: effects of the cannabinoid HU-210. Stroke 34, 2000-2006. doi: 10.1161/01.STR.0000079817.68944.1E

Lemberger, L., Axelrod, J., and Kopin, I. J. (1971). Metabolism and disposition of delta-9-tetrahydrocannabinol in man. Pharmacol. Rev. 23, 371-380.

Levine, A., Clemenza, K., Rynn, M., and Lieberman, J. (2017). Evidence for the risks and consequences of adolescent cannabis exposure. J. Am. Acad. Child Adolesc. Psychiatry 56, 214-225. doi: 10.1016/j.jaac.2016.12.014

Long, L. E., Chesworth, R., Huang, X. F., McGregor, I. S., Arnold, J. C., and Karl, T. (2013). Transmembrane domain Nrg1 mutant mice show altered susceptibility to the neurobehavioural actions of repeated THC exposure in adolescence. Int. J. Neuropsychopharmacol. 16, 163-175. doi: 10.1017/S1461145711001854

Ma, Y. L., Weston, S. E., Whalley, B. J., and Stephens, G. J. (2008). The phytocannabinoid Delta(9)-tetrahydrocannabivarin modulates inhibitory neurotransmission in the cerebellum. Br. J. Pharmacol. 154, 204-215. doi: 10.1038/bjp.2008.57

MacIntyre, J., Dong, A., Straiker, A., Zhu, J., Howlett, S. E., Bagher, A., et al. (2014). Cannabinoid and lipid-mediated vasorelaxation in retinal microvasculature. Eur. J. Pharmacol. 735, 105-114. doi: 10.1016/j.ejphar.2014.03.055

Mack, A. J. J. (2000). "Marijuana and Neurological Disorders," in (US) WDNAP (ed) Marijuana as Medicine? The Science Beyond the Controversy. (US: National Academies Press), 2000.

Maguire, M., Seidi, O., Baker, M., Gupta, A., and Muwanga, C. (2011). Acute mutism: a useful lesson. Emerg. Med. J. 28, 82-83. doi: 10.1136/ emj.2009.075788

Marder, C. P., Donohue, M. M., Weinstein, J. R., and Fink, K. R. (2012). Multimodal imaging of reversible cerebral vasoconstriction syndrome: a series of 6 cases. AJNR Am. J. Neuroradiol. 33, 1403-1410. doi: 10.3174/ajnr.A2964

Marijuana Overview (2019). http://www.ncsl.org/research/civil-and-criminaljustice/marijuana-overview.aspx (accessed 07-27-19 2019).

Marinella, M. A. (2001). Stroke after marijuana smoking in a teenager with factor V Leiden mutation. South Med. J. 94, 1217-1218.

Mateo, I., Pinedo, A., Gomez-Beldarrain, M., Basterretxea, J. M., and Garcia-Monco, J. C. (2005). Recurrent stroke associated with cannabis use. J. Neurol. Neurosurg. Psychiatry 76, 435-437. doi: 10.1136/jnnp.2004.042382

Mateo, I., Infante, J., Gomez Beldarrain, M., and Garcia-Monco, J. C. (2006). Cannabis and cerebrovascular disease. Neurologia 21, 204-208.

Matochik, J. A., Eldreth, D. A., Cadet, J. L., and Bolla, K. I. (2005). Altered brain tissue composition in heavy marijuana users. Drug Alcohol Depend. 77, 23-30. doi: 10.1016/j.drugalcdep.2004.06.011

McCarron, M. O., and Thomas, A. M. (1997). Cannabis and alcohol in stroke. Postgrad Med. J. 73, 448. doi: 10.1136/pgmj.73.861.448-a

Mecha, M., Feliu, A., Inigo, P. M., Mester, L., Carillo-Salinas, F. J., and Guaza, C. (2013). Cannabidiol provides long-lasting protection against the deleterious effects of inflammation in a viral model of multiple sclerosis: a role for A2A receptors. Neurobiol. Dis. 59, 141-150. doi: 10.1016/j.nbd.2013.06.016

Mesec, A., Rot, U., and Grad, A. (2001). Cerebrovascular disease associated with marijuana abuse: a case report. Cerebrovasc. Dis. 11, 284-285. doi: 10.1159/ 000047653

Milroy, C. M., and Parai, J. L. (2011). The histopathology of drugs of abuse. Histopathology 59, 579-593. doi: 10.1111/j.1365-2559.2010.03728.x

Mohan, H., and Sood, G. C. (1964). Conjugate deviation of the eyes after cannabis indica intoxication. Br. J. Ophthalmol. 48, 160-161. doi: 10.1136/bjo.48.3.160

Mouzak, A., Agathos, P., Kerezoudi, E., Mantas, A., and Vourdeli-Yiannakoura, E. (2000). Transient ischemic attack in heavy cannabis smokers-how 'safe' is it? Eur. Neurol. 44, 42-44. doi: 10.1159/000008191

Murikinati, S., Juttler, E., Keinert, T., Ridder, D. A., Muhammad, S., Waibler, Z., et al. (2010). Activation of cannabinoid 2 receptors protects against cerebral ischemia by inhibiting neutrophil recruitment. FASEB J. 24, 788-798. doi: 10.1096/fj.09-141275

Musshoff, F., and Madea, B. (2006). Review of biologic matrices (urine, blood, hair) as indicators of recent or ongoing cannabis use. Ther. Drug Monit 28, 155-163. doi: 10.1097/01.ftd.0000197091.07807.22

Naik, P., Fofaria, N., Prasad, S., Sajja, R. K., Weksler, B., Couraud, P. O., et al. (2014). Oxidative and pro-inflammatory impact of regular and denicotinized cigarettes on blood brain barrier endothelial cells: is smoking reduced or nicotine-free products really safe? BMC Neurosci. 15 , 51. doi: 10.1186/14712202-15-51 
National Academies of Sciences, Engineering, and Medicine. (2013). The Health Effects of Cannabis and Cannabinoids: The Current State of Evidence and Recommendations for Research. (Washington, DC: The National Academies Press). doi: $10.17226 / 24625$

NIDA. (2019a). Is there a link between marijuana use and psychiatric disorders? https://www.drugabuse.gov/publications/research-reports/marijuana/therelink-between-marijuana-use-psychiatric-disorders (accessed 08-04-19 2019).

NIDA. (2019b). Marijuana as Medicine, https://www.drugabuse.gov/publications/ drugfacts/marijuana-medicine (accessed 08-04-19 2019).

NIDA. (2018). Marijuana, https://www.drugabuse.gov/drugs-abuse/marijuana (accessed 08-04-19 2019).

Noskin, O., Jafarimojarrad, E., Libman, R. B., and Nelson, J. L. (2006). Diffuse cerebral vasoconstriction (Call-Fleming syndrome) and stroke associated with antidepressants. Neurology 67, 159-160. doi: 10.1212/01.wnl.0000223648.76430.27

Nouh, A., Ruland, S., Schneck, M. J., Pasquale, D., and Biller, J. (2014). Reversible cerebral vasoconstriction syndrome with multivessel cervical artery dissections and a double aortic arch. J. Stroke Cerebrovasc. Dis. 23, e141-e143. doi: 10.1016/j.jstrokecerebrovasdis.2013.08.013

Ntlholang, O., McDonagh, R., Nicholson, S., Brett, F., Bradley, D., and Harbison, J. (2015). Is intimal hyperplasia associated with cranial arterial stenosis in cannabis-associated cerebral infarction? Int. J. Stroke 10, E56-E59. doi: $10.1111 /$ ijs. 12521

O'Sullivan, S. E. (2016). An update on PPAR activation by cannabinoids. Br. J. Pharmacol. 173, 1899-1910. doi: 10.1111/bph.13497

O’Tuathaigh, C. M., Hryniewiecka, M., Behan, A., Tighe, O., Coughlan, C., Desbonnet, L., et al. (2010). Chronic adolescent exposure to Delta-9-tetrahydrocannabinol in COMT mutant mice: impact on psychosis-related and other phenotypes. Neuropsychopharmacology 35, 2262-2273. doi: 10.1038/npp.2010.100

Omar, M. E. (2015). Abdel-Salam ERYAKAMFA-RAOAS. The effect of cannabis on oxidative stress and neurodegeneration induced by intrastriatal rotenone injection in rats. Comp. Clin. Pathol. 24, 17. doi: 10.1007/s00580-014-1907-9

Owens, S. M., McBay, A. J., Reisner, H. M., and Perez-Reyes, M. (1981). 125I radioimmunoassay of delta-9-tetrahydrocannabinol in blood and plasma with a solid-phase second-antibody separation method. Clin. Chem. 27, 619-624.

Oyinloye, O., Nzeh, D., Yusuf, A., and Sanya, E. (2014). Ischemic stroke following abuse of Marijuana in a Nigerian adult male. J. Neurosci. Rural Pract. 5, 417419. doi: $10.4103 / 0976-3147.140008$

Parmentier-Batteur, S., Jin, K., Mao, X. O., Xie, L., and Greenberg, D. A. (2002). Increased severity of stroke in $\mathrm{CB} 1$ cannabinoid receptor knock-out mice. $J$. Neurosci. 22, 9771-9775. doi: 10.1523/JNEUROSCI.22-22-09771.2002

Perucca, E. (2017). Cannabinoids in the treatment of epilepsy: hard evidence at last? J. Epilepsy Res. 7, 61-76. doi: 10.14581/jer.17012

Prasad, S., Sajja, R. K., Kaisar, M. A., Park, T. H., Villalba, H., Liles, T., et al. (2017). Role of Nrf2 and protective effects of Metformin against tobacco smokeinduced cerebrovascular toxicity. Redox Biol. 12, 58-69. doi: 10.1016/ j.redox.2017.02.007

Pun, P. B., Lu, J., and Moochhala, S. (2009). Involvement of ROS in BBB dysfunction. Free Radic. Res. 43, 348-364. doi: 10.1080/10715760902751902

Raheemullah, A., and Laurence, T. N. (2016). Repeated thrombosis after synthetic cannabinoid use. J. Emerg. Med. 51, 540-543. doi: 10.1016/j.jemermed.2016. 06.015

Ray, W. Z., Krisht, K. M., Schabel, A., and Schmidt, R. H. (2013). Subarachnoid hemorrhage from a thoracic radicular artery pseudoaneurysm after methamphetamine and synthetic cannabinoid abuse: case report. Global Spine J. 3, 119-124. doi: 10.1055/s-0032-1331463

Renard, D., and Gaillard, N. (2008). Brain haemorrhage and cerebral vasospasm associated with chronic use of cannabis and buprenorphine. Cerebrovasc. Dis. 25, 282-283. doi: $10.1159 / 000119638$

Renard, D., Taieb, G., Gras-Combe, G., and Labauge, P. (2012). Cannabis-related myocardial infarction and cardioembolic stroke. J. Stroke Cerebrovasc. Dis. 21, 82-83. doi: 10.1016/j.jstrokecerebrovasdis.2010.04.002

Richter, J. S., Quenardelle, V., Rouyer, O., Raul, J. S., Beaujeux, R., Geny, B., et al. (2018). A systematic review of the complex effects of cannabinoids on cerebral and peripheral circulation in animal models. Front. Physiol. 9, 622. doi: 10.3389/fphys.2018.00622

Rivera-Olmos, V. M., and Parra-Bernal, M. C. (2016). Cannabis: effects in the central nervous system. therapeutic, societal and legal consequences. Rev. Med. Inst. Mex Seguro Soc. 54, 626-634.
Rivers-Auty, J. R., Smith, P. F., and Ashton, J. C. (2014). The cannabinoid CB2 receptor agonist GW405833 does not ameliorate brain damage induced by hypoxia-ischemia in rats. Neurosci. Lett. 569, 104-109. doi: 10.1016/ j.neulet.2014.03.077

Robert, T., Kawkabani Marchini, A., Oumarou, G., and Uske, A. (2013). Reversible cerebral vasoconstriction syndrome identification of prognostic factors. Clin. Neurol. Neurosurg. 115, 2351-2357. doi: 10.1016/j.clineuro.2013.08.014

Rose, D. Z., Guerrero, W. R., Mokin, M. V., Gooch, C. L., Bozeman, A. C., Pearson, J. M., et al. (2015). Hemorrhagic stroke following use of the synthetic marijuana "spice". Neurology 85, 1177-1179. doi: 10.1212/WNL.0000000000001973

Rumalla, K., Reddy, A. Y., and Mittal, M. K. (2016a). Recreational marijuana use and acute ischemic stroke: a population-based analysis of hospitalized patients in the United States. J. Neurol. Sci. 364, 191-196. doi: 10.1016/j.jns.2016.01.066

Rumalla, K., Reddy, A. Y., and Mittal, M. K. (2016b). Association of recreational marijuana use with aneurysmal subarachnoid hemorrhage. J. Stroke Cerebrovasc. Dis. 25, 452-460. doi: 10.1016/j.jstrokecerebrovasdis.2015.10.019

Russmann, S., Winkler, A., Lovblad, K. O., Stanga, Z., and Bassetti, C. (2002). Lethal ischemic stroke after cisplatin-based chemotherapy for testicular carcinoma and cannabis inhalation. Eur. Neurol. 48, 178-180. doi: 10.1159/ 000065511

Sajja, R. K., Green, K. N., and Cucullo, L. (2015). Altered Nrf2 signaling mediates hypoglycemia-induced blood-brain barrier endothelial dysfunction in vitro. PloS One 10, 17. doi: 10.1371/journal.pone.0122358

Sajja, R. K., Kaisar, M. A., Vijay, V., Desai, V. G., Prasad, S., and Cucullo, L. (2018). In vitro modulation of redox and metabolism interplay at the brain vascular endothelium: genomic and proteomic profiles of sulforaphane activity. Sci. Rep. 8, 12708. doi: 10.1038/s41598-018-31137-7

Santos, A. F., Rodrigues, M., Mare, R., Ferreira, C., Soares-Fernandes, J., and Rocha, J. (2014). Recurrent stroke in a young cannabis user. J. Neuropsychiatry Clin. Neurosci. 26, E41-E42. doi: 10.1176/appi.neuropsych.13020037

Sarafian, T. A., Magallanes, J. A., Shau, H., Tashkin, D., and Roth, M. D. (1999). Oxidative stress produced by marijuana smoke. An adverse effect enhanced by cannabinoids. Am. J. Respir. Cell Mol. Biol. 20, 1286-1293. doi: 10.1165/ ajrcmb.20.6.3424

Schulenberg, J. E., Johnston, L. D., O’Malley, P. M., Bachman, J. G., Miech, R. A., and Patrick, M. E. (2018). Monitoring the Future national survey results on drug use, 1975-2017. Ann Arbor: Institute for Social Research, The University of Michigan.

Schulenberg, J. E., Johnston, L. L. D., O’Malley, P. M., Bachman, J. G., Miech, R. A., and Patrick, M. E. (2018). Monitoring the Future national survey results on drug use, 1975-2017: Volume II, College students and adults ages 19-55. Ann Arbor: Institute for Social Research, The University of Michigan. http:// monitoringthefuture.org/pubs.html\#monographs

Scutt, A., and Williamson, E. M. (2007). Cannabinoids stimulate fibroblastic colony formation by bone marrow cells indirectly via CB2 receptors. Calcif. Tissue Int. 80, 50-59. doi: 10.1007/s00223-006-0171-7

Segal-Gavish, H., Gazit, N., Barhum, Y., Ben-Zur, T., Taler, M., Hornfeld, S. H., et al. (2017). BDNF overexpression prevents cognitive deficit elicited by adolescent cannabis exposure and host susceptibility interaction. Hum. Mol. Genet. 26, 2462-2471. doi: $10.1093 / \mathrm{hmg} / \mathrm{ddx} 139$

Sharma, P., Murthy, P., and Bharath, M. M. (2012). Chemistry, metabolism, and toxicology of cannabis: clinical implications. Iran J. Psychiatry 7, 149-156.

Sharma, D., Dahal, U., and Yu, E. (2019). Complete occlusion of bilateral internal carotid artery in a marijuana smoker: a case report. J. Clin. Med. Res. 11, 305308. doi: 10.14740/jocmr3132w

Shen, M., Piser, T. M., Seybold, V. S., and Thayer, S. A. (1996). Cannabinoid receptor agonists inhibit glutamatergic synaptic transmission in rat hippocampal cultures. J. Neurosci. 16, 4322-4334. doi: 10.1523/ JNEUROSCI.16-14-04322.1996

Shere, A., and Goyal, H. (2017). Cannabis can augment thrombolytic properties of rtPA: Intracranial hemorrhage in a heavy cannabis user. Am. J. Emerg. Med. 35, e1981-e1988. doi: 10.1016/j.ajem.2017.09.049

Sherpa, D., Paudel, B. M., Subedi, B. H., and Chow, R. D. (2015). Synthetic cannabinoids: the multi-organ failure and metabolic derangements associated with getting high. J. Community Hosp. Intern. Med. Perspect. 5, 27540. doi: 10.3402/jchimp.v5.27540

Sierra, S., Luquin, N., Rico, A. J., Gomez-Bautista, V., Roda, E., Dopeso-Reyes, I. G., et al. (2015). Detection of cannabinoid receptors $\mathrm{CB} 1$ and $\mathrm{CB} 2$ within basal ganglia 
output neurons in macaques: changes following experimental parkinsonism. Brain Struct. Funct. 220, 2721-2738. doi: 10.1007/s00429-014-0823-8

Singh, N. N., Pan, Y., Muengtaweeponsa, S., Geller, T. J., and Cruz-Flores, S. (2012). Cannabis-related stroke: case series and review of literature. J. Stroke Cerebrovasc. Dis. 21, 555-560. doi: 10.1016/j.jstrokecerebrovasdis.2010.12.010

Singh, A., Saluja, S., Kumar, A., Agrawal, S., Thind, M., Nanda, S., et al. (2018). Cardiovascular complications of marijuana and related substances: a review. Cardiol. Ther. 7, 45-59. doi: 10.1007/s40119-017-0102-x

Singhal, A. B., Hajj-Ali, R. A., Topcuoglu, M. A., Fok, J., Bena, J., Yang, D., et al. (2011). Reversible cerebral vasoconstriction syndromes: analysis of 139 cases. Arch. Neurol. 68, 1005-1012. doi: 10.1001/archneurol.2011.68

Sivandzade, F., and Cucullo, L. (2018). In-vitro blood-brain barrier modeling: a review of modern and fast-advancing technologies. J. Cereb. Blood Flow Metab. 38, 1667-1681. doi: 10.1177/0271678X18788769

Sivandzade, F., Prasad, S., Bhalerao, A., and Cucullo, L. (2019). NRF2 and NF-B interplay in cerebrovascular and neurodegenerative disorders: molecular mechanisms and possible therapeutic approaches. Redox Biol. 21, 101059. doi: 10.1016/j.redox.2018.11.017

State Medical Marijuana Laws (2019). http://www.ncsl.org/research/health/statemedical-marijuana-laws.aspx (accessed 07-27-19 2019).

Stein, E. A., Fuller, S. A., Edgemond, W. S., and Campbell, W. B. (1998). Selective effects of the endogenous cannabinoid arachidonylethanolamide (anandamide) on regional cerebral blood flow in the rat. Neuropsychopharmacology 19, 481-491. doi: 10.1016/S0893-133X(98)00043-8

Su, E. N., Kelly, M. E., Cringle, S. J., and Yu, D. Y. (2015). Role of endothelium in abnormal cannabidiol-induced vasoactivity in retinal arterioles. Invest. Ophthalmol. Vis Sci. 56, 4029-4037. doi: 10.1167/iovs.14-14879

Szutorisz, H., and Hurd, Y. L. (2018). High times for cannabis: epigenetic imprint and its legacy on brain and behavior. Neurosci. Biobehav. Rev. 85, 93-101. doi: 10.1016/j.neubiorev.2017.05.011

Takematsu, M., Hoffman, R. S., Nelson, L. S., Schechter, J. M., Moran, J. H., and Wiener, S. W. (2014). A case of acute cerebral ischemia following inhalation of a synthetic cannabinoid. Clin. Toxicol. (Phila) 52, 973-975. doi: 10.3109/ 15563650.2014.958614

Tantra, M., Krocher, T., Papiol, S., Winkler, D., Rockle, I., Jatho, J., et al. (2014). St8sia2 deficiency plus juvenile cannabis exposure in mice synergistically affect higher cognition in adulthood. Behav. Brain Res. 275, 166-175. doi: 10.1016/ j.bbr.2014.08.062

Termote, B., Verswijvel, G., Gelin, G., and Palmers, Y. (2007). Cannabis-induced brain ischemia. JBR-BTR 90, 218-219.

Thanvi, B. R., and Treadwell, S. D. (2009). Cannabis and stroke: is there a link? Postgrad Med. J. 85, 80-83. doi: 10.1136/pgmj.2008.070425

Thomas, G., Kloner, R. A., and Rezkalla, S. (2014). Adverse cardiovascular, cerebrovascular, and peripheral vascular effects of marijuana inhalation: what cardiologists need to know. Am. J. Cardiol. 113, 187-190. doi: 10.1016/ j.amjcard.2013.09.042

Tirkey, N. K., and Gupta, S. (2016). Acute antero-inferior wall ischaemia with acute ischaemic stroke caused by oral ingestion of cannabis in a young male. J. Assoc. Physicians India 64, 93-94.

Trojak, B., Leclerq, S., Meille, V., Khoumri, C., Chauvet-Gelinier, J. C., Giroud, M., et al. (2011). Stroke with neuropsychiatric sequelae after cannabis use in a man: a case report. J. Med. Case Rep. 5, 264. doi: 10.1186/1752-1947-5-264

Tsivgoulis, G., Lachanis, S., Papathanasiou, M. A., Chondrogianni, M., Brountzos, E. N., and Voumvourakis, K. (2014). Cannabis-associated angiopathy: an uncommon cause of crescendo transient ischemic attacks. Circulation 130, 2069-2070. doi: 10.1161/CIRCULATIONAHA.114.013164

Turcotte, C., Blanchet, M. R., Laviolette, M., and Flamand, N. (2016). The CB2 receptor and its role as a regulator of inflammation. Cell Mol. Life Sci. 73, 44494470. doi: $10.1007 /$ s00018-016-2300-4

Vandevenne, M., Vandenbussche, H., and Verstraete, A. (2000). Detection time of drugs of abuse in urine. Acta Clin. Belg. 55, 323-333. doi: 10.1080/ 17843286.2000 .11754319

Vijayan, M., Alamri, F. F., Al Shoyaib, A., Karamyan, V. T., and Reddy, P. H. (2019). Novel miRNA PC-5P-12969 in ischemic stroke. Mol. Neurobiol. 56, 6976-6985. doi: 10.1007/s12035-019-1562-x

Volpon, L. C., Sousa, C., Moreira, S. K. K., Teixeira, S. R., and Carlotti, A. (2017). Multiple cerebral infarcts in a young patient associated with marijuana use. J. Addict. Med. 11, 405-407. doi: 10.1097/ADM.0000000000000326
Westover, A. N., McBride, S., and Haley, R. W. (2007). Stroke in young adults who abuse amphetamines or cocaine: a population-based study of hospitalized patients. Arch. Gen. Psychiatry 64, 495-502. doi: 10.1001/archpsyc.64.4.495

Whitlock, J. B., Robinson, G. T., Whitlock, J. P., Dredla, B. K., and Barrett, K. M. (2015). Mystery case: a 21-year-old man with visual loss following marijuana use. Neurology 84, e165-e169. doi: 10.1212/WNL.0000000000001627

Winkler, E. A., Bell, R. D., and Zlokovic, B. V. (2011). Central nervous system pericytes in health and disease. Nat. Neurosci. 14, 1398-1405. doi: 10.1038/nn.2946

Wolff, V., and Jouanjus, E. (2017). Strokes are possible complications of cannabinoids use. Epilepsy Behav. 70, 355-363. doi: 10.1016/j.yebeh.2017.01.031

Wolff, V., Lauer, V., Rouyer, O., Sellal, F., Meyer, N., Raul, J. S., et al. (2011). Cannabis use, ischemic stroke, and multifocal intracranial vasoconstriction: a prospective study in 48 consecutive young patients. Stroke $42,1778-1780$. doi: 10.1161/STROKEAHA.110.610915

Wolff, V., Armspach, J. P., Lauer, V., Rouyer, O., Bataillard, M., Marescaux, C. et al. (2013). Cannabis-related stroke: myth or reality? Stroke 44, 558-563. doi: 10.1161/STROKEAHA.112.671347

Wolff, V., Armspach, J. P., Beaujeux, R., Manisor, M., Rouyer, O., Lauer, V., et al. (2014). High frequency of intracranial arterial stenosis and cannabis use in ischaemic stroke in the young. Cerebrovasc. Dis. 37, 438-443. doi: 10.1159/ 000363618

Wolff, V., Armspach, J. P., Lauer, V., Rouyer, O., Ducros, A., Marescaux, C., et al. (2015a). Ischaemic strokes with reversible vasoconstriction and without thunderclap headache: a variant of the reversible cerebral vasoconstriction syndrome? Cerebrovasc. Dis. 39, 31-38. doi: 10.1159/000369776

Wolff, V., Schlagowski, A. I., Rouyer, O., et al. (2015b). Tetrahydrocannabinol induces brain mitochondrial respiratory chain dysfunction and increases oxidative stress: a potential mechanism involved in cannabis-related stroke. BioMed. Res. Int. 2015 (2015), 323706. doi: 10.1155/2015/323706

Wu, C. S., Jew, C. P., and Lu, H. C. (2011). Lasting impacts of prenatal cannabis exposure and the role of endogenous cannabinoids in the developing brain. Future Neurol. 6, 459-480. doi: 10.2217/fnl.11.27

Yang, C., Hawkins, K. E., Dore, S., and Candelario-Jalil, E. (2019). Neuroinflammatory mechanisms of blood-brain barrier damage in ischemic stroke. Am. J. Physiol. Cell Physiol. 316, C135-C153. doi: 10.1152/ajpcell.00136.2018

Yau, W. Y., Chu, E., and Lai, N. (2015). Cannabis, serotonergic drug use and stroke in a 50-year-old woman. Intern. Med. J. 45, 1312-1313. doi: 10.1111/imj.12933

Yucel, M., Solowij, N., Respondek, C., Whittle, S., Fornito, A., Pantelis, C., et al. (2008). Regional brain abnormalities associated with long-term heavy cannabis use. Arch. Gen. Psychiatry 65, 694-701. doi: 10.1001/archpsyc.65.6.694

Zachariah, S. B. (1991). Stroke after heavy marijuana smoking. Stroke 22, 406-409. doi: 10.1161/01.str.22.3.406

Zalesky, A., Solowij, N., Yucel, M., Lubman, D. I., Takagi, M., Harding, I. H., et al. (2012). Effect of long-term cannabis use on axonal fibre connectivity. Brain 135, 2245-2255. doi: 10.1093/brain/aws136

Zarruk, J. G., Fernandez-Lopez, D., Garcia-Yebenes, I., Garcia-Gutierrez, M. S., Vivancos, J., Nombela, F., et al. (2012). Cannabinoid type 2 receptor activation downregulates stroke-induced classic and alternative brain macrophage/ microglial activation concomitant to neuroprotection. Stroke 43, 211-219. doi: 10.1161/STROKEAHA.111.631044

Zhang, M., Martin, B. R., Adler, M. W., Razdan, R. K., Jallo, J. I., and Tuma, R. F. (2007). Cannabinoid $\mathrm{CB}(2)$ receptor activation decreases cerebral infarction in a mouse focal ischemia/reperfusion model. J. Cereb. Blood Flow Metab. 27, 1387-1396. doi: 10.1038/sj.jcbfm.9600447

Zou, S., and Kumar, U. (2018). Cannabinoid receptors and the endocannabinoid system: signaling and function in the central nervous system. Int. J. Mol. Sci. 19, 833. doi: $10.3390 /$ ijms 19030833

Conflict of Interest: The authors declare that the research was conducted in the absence of any commercial or financial relationships that could be construed as a potential conflict of interest.

Copyright $\odot 2019$ Archie and Cucullo. This is an open-access article distributed under the terms of the Creative Commons Attribution License (CC BY). The use, distribution or reproduction in other forums is permitted, provided the original author(s) and the copyright owner(s) are credited and that the original publication in this journal is cited, in accordance with accepted academic practice. No use, distribution or reproduction is permitted which does not comply with these terms. 